8-15-2014

\title{
A Comparison of Teaching Methods in Taiwan for Young Learners of English
}

Marilyn E. Hodgin

Cedarville University

Follow this and additional works at: http://digitalcommons.cedarville.edu/education_theses

Part of the Bilingual, Multilingual, and Multicultural Education Commons, Educational Methods Commons, and the International and Comparative Education Commons

\section{Recommended Citation}

Hodgin, Marilyn E., "A Comparison of Teaching Methods in Taiwan for Young Learners of English" (2014). Master of Education Research Theses. 68.

http://digitalcommons.cedarville.edu/education_theses/68 
A Comparison of Teaching Methods

in Taiwan for Young Learners of English

A thesis submitted in partial fulfillment

of the requirements for the degree of

Master of Education

By

Marilyn E. Hodgin

B.A. English, Western Michigan University, 1973

Cedarville University

2014 


\begin{abstract}
The purpose of this research is to investigate what instructional methods are effectively being used in Taiwanese primary school classrooms to increase the abilities of students' speaking and listening of English. The data for this qualitative study was collected from three sources. One was from a short survey of eight local teachers in the sample population. Another was from individual interviews with each of those instructors. The third was personal observations from the English classrooms while teaching in Taiwan. Most of the teachers were from the public schools, but two were private English instructors. Three themes emerged from the coding of the interviews. The first included the instructional methods that the teachers employed in their classrooms. The second theme related to the challenges the teachers faced in teaching the English language. The final theme was composed of suggestions from the teachers to improve the task of teaching English to the students in the primary grades from a local and national perspective. A comparison of methods and outcomes was made between the public and private instructors.
\end{abstract}

Keywords: young learners, teaching English, instruction al methods, Taiwan 


\section{Acknowledgements}

In an attempt to give thanks to all who have journeyed with me on this project, I must first give thanks to the greatest guide and my constant companion, my Lord Jesus Christ. He is the one who has given me the desires of my heart by allowing me to pursue my Master's degree while teaching overseas. I also want to thank my children, Jonathan, Daniel, Melinda, Benjamin, and Rachel, who gave their encouragement to me from the other side of the world. While working on completing the writing, Rebecca and David provided insightful comments for which I am very grateful. I would also like to express my appreciation to my advisor, Dr. Timothy Heaton, for his time, support, and advice. Thanks also are given to Dr. Hwang and Dr. Ager for reviewing this research and for being a part of the thesis committee. Special thanks go to the participants in my research who allowed me to ask questions in a language that was not their first language, and who made this research possible. 


\section{TABLE OF CONTENTS}

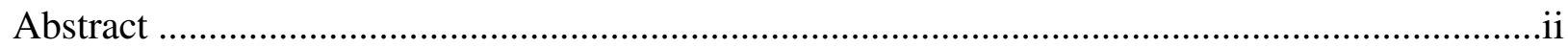

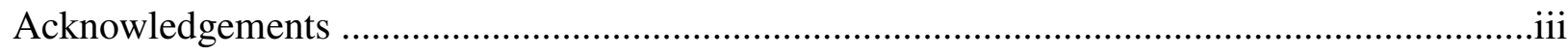

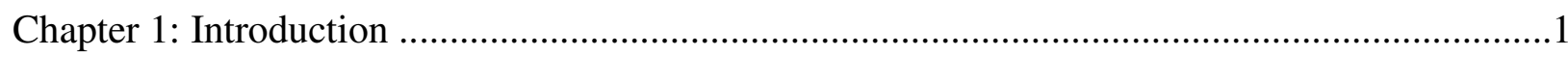

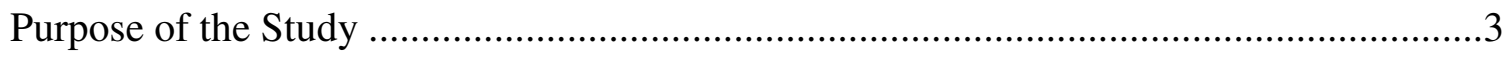

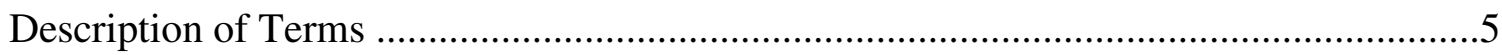

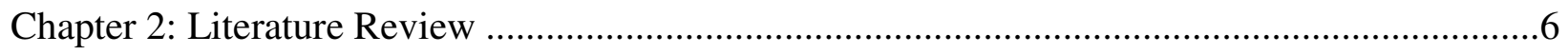

English Instruction for Young Learners ..............................................................6

Taiwan's English Instruction in the Elementary Grades .........................................

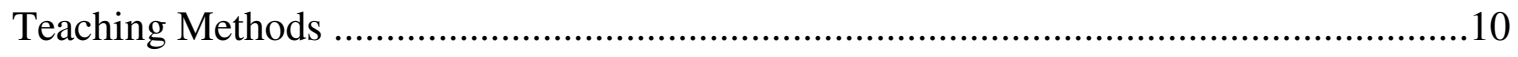

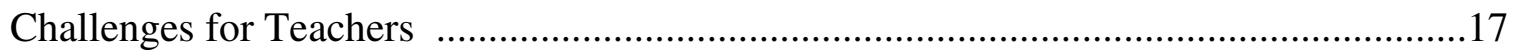

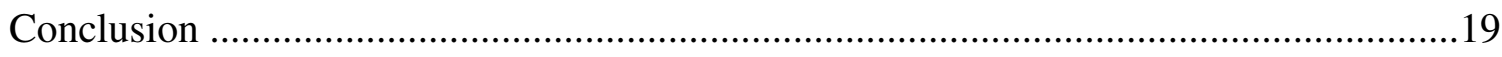

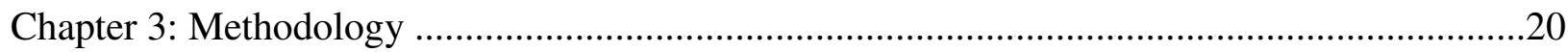

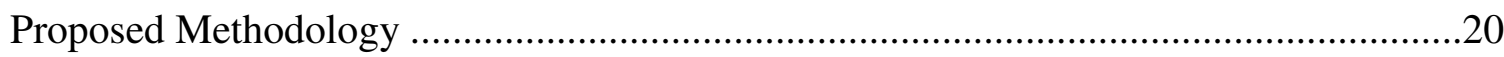

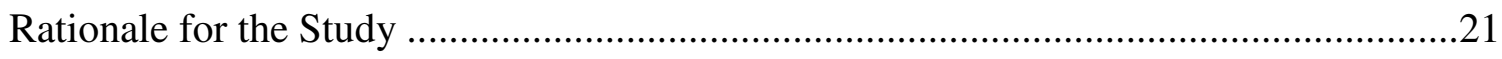

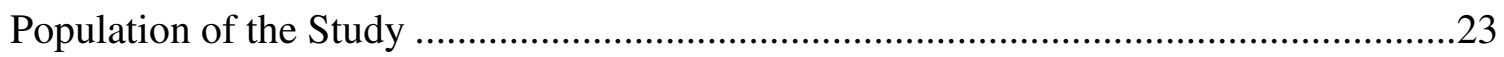

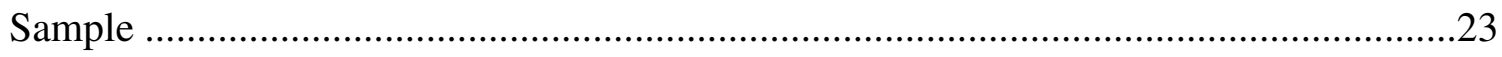

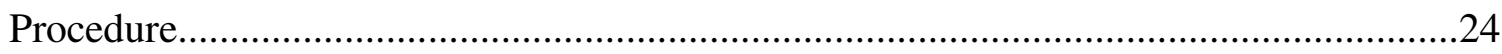

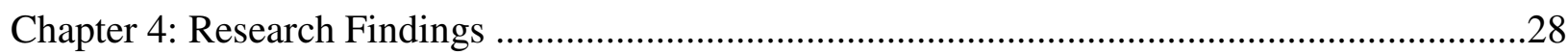

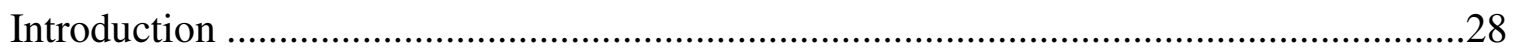

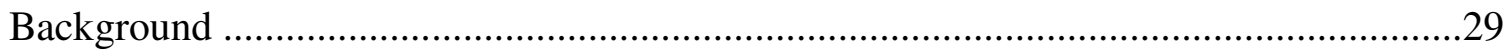

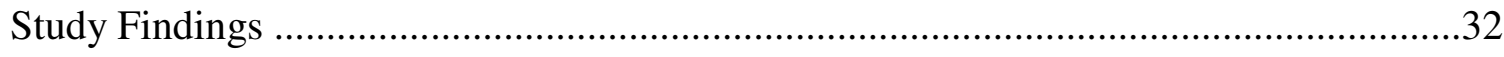

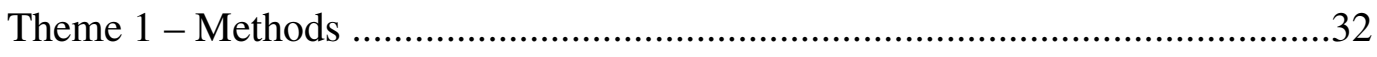

Public School Teachers ......................................................................33

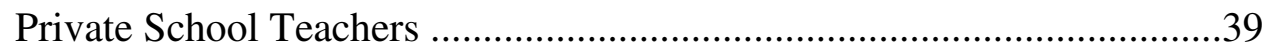


Theme 2 - Challenges .......................................................................42

Public School Teachers ..................................................................42

Private School Teachers ..................................................................44

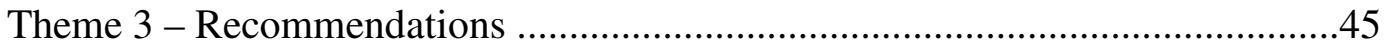

Public School Teachers ..................................................................45

Private School Teachers ...............................................................4 47

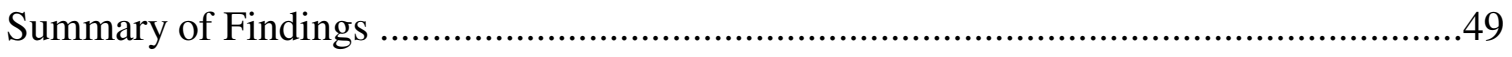

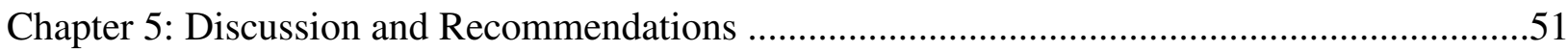

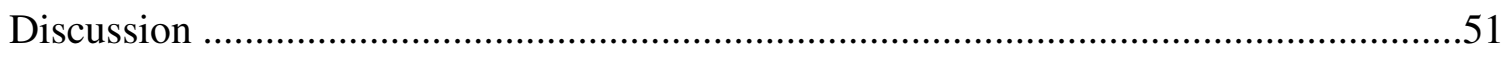

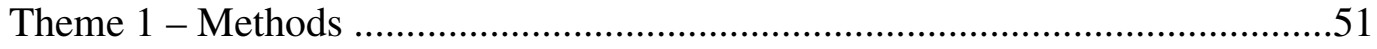

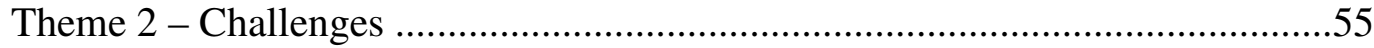

Theme 3 - Recommendations ....................................................................56

Teaching Methods of a Master Teacher ..............................................................60

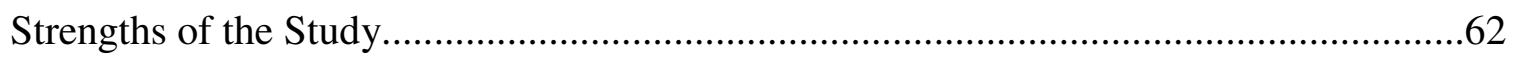

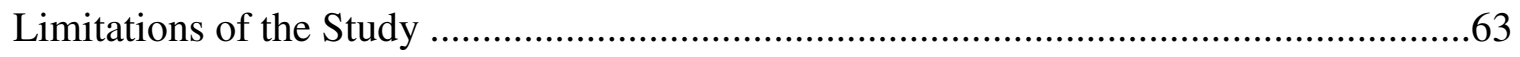

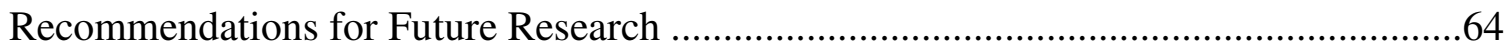

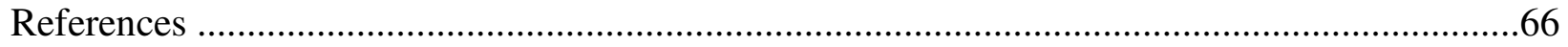

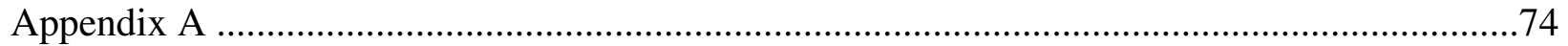

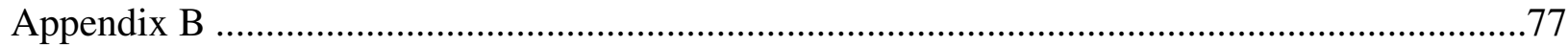

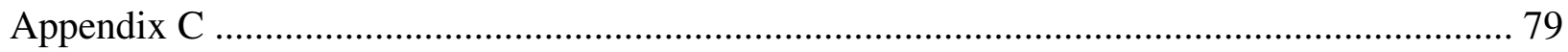

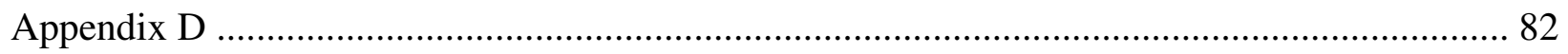




\section{A Comparison Of Teaching Methods \\ In Taiwan For Young Learners Of English}

English is a language that has a global impact and is considered necessary in many parts of the world in the pursuit of economic and educational growth. As a result, many countries whose native language is something other than English have begun to incorporate the instruction of English (Nunan, 2003). Because of the globalization of English, the English language "has become a bridge in international communication" (Chen, 2005). In many East Asian countries, the pattern had been to include English instruction in secondary schools, but now they have begun to add instruction at the elementary level. Currently, Taiwan, Japan, and Korea provide English in the public elementary schools in third grade, with some districts offering instruction as low as the kindergarten level. In 2001, Taiwan began to offer English in the fifth grade, and then lowered it to third grade in 2005 (Ministry of Education (Taiwan), 2004; Chern, n.d.).

With English instruction offered in more grade levels, the need arose for more English teachers. In Taiwan, the government looked at different ways to meet that need. Because of a limited number of native English speakers in the country of Taiwan, the remaining resource was teachers whose confidence in their English language abilities was limited. The government of Taiwan decided to develop a program to invite native English speakers who were also certified

teachers to teach in a local public school for a school year. That program began in 2004 with the Ministry of Education bringing licensed teachers to Taiwan from the United States and Canada (Ministry of Education, (Taiwan), 2013a).

The Ministry of Education in Taiwan has promoted the Foreign English Teachers in Taiwan program in the hope that: 
“1) Participating teachers will grow professionally as a result of the exchange of instructional practices and strategies, 2) Students in Taiwan will gain first-hand knowledge, appreciation, and understanding of the English language, and 3) All participating countries benefit from this collaborative relationship, which enhances international awareness and understanding” (Ministry of Education (Taiwan), 2013b). With all the emphasis being placed on the inclusion of English in the elementary curriculum, the teachers are facing a daunting task. The new direction in education brings with it new challenges for the teachers.

For this researcher, hearing from people who had traveled the world to teach peoples of different languages and cultures was a very enjoyable activity from childhood. Most of them were missionaries who stayed in homes while back in the States for a visit. One of the childhood dreams of this researcher was to teach overseas. When the opportunity to teach in Taiwan was presented, that dream became a reality. She had the privilege of teaching English for four years in Taiwan with a program that was initiated by the Ministry of Education. One thing that was noticed early in Taiwan was the number of students who attended a cram school (private learning center) in the evenings, as well as during winter and summer break. Academic opportunities in Taiwan are based on a student's ability to pass a proficiency test that determines what level of school he/she will be able to attend. With the pressure of preparing for the tests, students attend the private schools to receive additional focused instruction with the hopes of doing well enough on the test to allow them to go to a more challenging school.

With all of the time the students spend in school, both public and private, it was observed that students and teachers were very reluctant to speak English. While speaking with other foreign English teachers, the same dilemma was consistent with students not being able or 
willing to speak English. Other research done in Taiwan noted that in spite of the desire for more English, there had not been much improvement (So, n.d.). DeCapua and Wintergerst noted that the response was often silence accompanied by a reluctance to ask questions or engage in discussion (as cited in Yek, 2006). Nunan included some observations that even university students were not very proficient in their ability to communicate. This researcher noted that talking with some professors of English in Taiwan, they mentioned the very same quandary with their students' reticence to speak the English language. Because of the recurring pattern observed with the students, the idea of doing research on local teaching methods and outcomes began to take root in possibilities for in-depth study. Language instruction and learning are very complex and can be very intimidating. The question of whether what had been observed on a local school level was being addressed in the research that had been done on a larger scale. A look at the English teachers' methods, challenges, and the outcomes of the instruction in Taiwan, beginning with a literature review, will be the foundation for the research that will be done in this study.

The framework for this research is a comparative study based on the controlled variables of the teacher's methods and the results they produce. The comparison will be between the teachers in the public schools and the private schools and the outcomes of their instruction. In the results of the interviews, the uncontrolled variables will be the children's inherent abilities to learn, input or help from the parents, and the income or economic level of the family. Because this research will be conducted with local teachers, the scope will be limited in size, but the results will expectantly be applicable to a broader base of instructors and instruction.

\section{Purpose of the Study}

Because the required teaching of English to students who are learning the language in the primary grades is relatively new, the research that has been conducted is much less than that 
done on secondary and tertiary levels. Research on private schools that teach primary students is even less. This study takes a look at the literature on this subject to see what the results of the research have found. The intent of the proposed study is to investigate the teaching of English at the local elementary level from both public and private school teachers' perspectives, including their teaching methods and outcomes, and what challenges they face. The focus will be on local teachers' methods used in their school setting and the outcomes of their instruction and then compare the two school settings to see what the results have been. The research will be conducted with local English teachers in Taiwan to compare the public and private school teaching.

The questions that will be addressed are as follows:

1. What instructional methods used in the classroom for teaching a second language are effective in increasing the receptive and productive dimension of English for young learners?

2. Do private schools have different methods, outcomes, and challenges than public schools?

These are the central questions, but through the research, more questions might be raised. It is anticipated that the findings on methods and outcomes of teaching English will be varied. The teaching methods might be connected to the traditional teaching methods in different cultural settings. It is also expected that the results found in the research will match what has been observed in teaching at the different primary schools. Throughout the research, the goal will be to find methods that have been found to produce positive outcomes in the language acquisition and use of the English language. Finding similar results on a local level as to what has been observed on a larger scale will be the anticipated results. Looking at the 
effective teaching methods found in the literature will be the basis for suggestions in providing solutions to the challenges the English teachers face.

\section{Description of Terms}

BEP - bilingual environmental print, signs for different places and English learning related posters (Yeh \& Teng, 2010).

CLT - Communicative Language Teaching, instruction with a focus on communication skills development (Enever \& Moon, 2010).

Constructivist education - learning environment that motivates, engages, and equips learners to build their own learning (Motlhaka, 2012).

Cram schools - private schools that operate in afternoons, evenings, and weekends with focused instruction in specific subject areas (Her, 2007).

EFL - English as a Foreign Language, (Wang, 2009).

ESL - English as a Second Language (Motlhaka, 2012).

ESOL - English to Students of Other Languages (Mukoroli, 2011).

KK symbols - Kenyon and Knott, authors of A Pronouncing Dictionary of American English, which is a method of phonemic transcription of English words, similar to the IPA (International Phonetic Alphabet), (So, n.d.).

MOE - Ministry of Education in Taiwan, (Wang, 2009).

SIOP - Sheltered Instruction Observation Protocol, features of sheltered instruction that enhance instructional practice in the teaching of English (Echevarria, Vogt, and Short, 2004).

TPR - total physical response, coordinating language with physical movement (Wang, 2008). 


\section{Chapter 2 - Literature Review}

In this section, pertinent literature on issues of concern to this study will be reviewed. The chapter consists of four parts. In the first, there will be a brief discussion about the basis for English instruction for young learners. In the second, the review will examine the history and reasoning by the Ministry of Education in Taiwan to include instruction in English at the primary grade level. The last two sections deal with teaching methods and then the challenges faced by English teachers.

\section{English Instruction for Young Learners}

In looking at literature about teaching in the elementary school, a foundational topic in the research dealt with the best time to begin instruction for a second language. The Ministry of Education in Taiwan implemented the Nine Year Integrated Curriculum for Elementary and Junior High Schools where they stated that the English instruction needed to begin in elementary school to take advantage of the optimal period of language learning (Chern, n.d.). Enever, Moon, and Raman found that young children are better learners because they find language learning easier, which provides a longer period for them to acquire a higher language proficiency (Enever, Moon \& Raman, 2009). Parents were also reported as being supportive of beginning English instruction at an earlier age. Chang found that over $80 \%$ of the responses supported beginning instruction earlier than third grade (Chang, 2008).

Because English is a foreign language, starting early could help develop a positive outlook towards learning a new language ( $\mathrm{Su}, 1998)$. If English is introduced at the primary level, the students would have a higher language acquisition level just because of the longevity of instruction, and provide more equity for all of the student population (Enever, Moon, \& 
Raman, 2009). This would result in a student population that would be more proficient in English, resulting in greater opportunities in the future (Lin, 2012).

Research has found, however, that young children develop at a slower pace than older students and adults (Nikolov, 2009). Research done on second language learners who were learning a European language showed that the younger students made less progress in acquiring the language than the older ones.

Another study looked at five myths relating to young learners and acquisition of a new language (McLaughlin, 1992). Studies have shown that children learn a second language much easier, but the measure used in determining communication between children and adult is very different. A myth that applies to this research is that once a child has learned the second language then they can communicate with it. The study found that even though a child has the ability to speak the language, they could still be having difficulty in reading and writing that involves academic language. The longevity of instruction for the older language learners provides a strong foundation for mastery in the second language if they demonstrate academic proficiency in the first language (Cummins, 1980). This is also supported by Cummins' work that differentiated between basic intercommunication skills (BICS) and cognitive academic language proficiency (CALP) (Cummins, 1999). McLaughlin challenged the myth that children all learn a second language the same way. Because language learners bring with them diverse cultural backgrounds, they also bring with them a diverse array of instructional needs (McLaughlin, 1992).

\section{Taiwan's English Instruction in the Elementary Grades}

Enever, Moon, and Raman noted that English acquisition globally is considered a measure of academic achievement (Enever, Moon, \& Raman, 2009). Taiwan began the task of 
increasing their academic standing globally by revamping the goals and strategies in education. The MOE (Ministry of Education) has taken some very aggressive strides towards implementing a more efficient framework for all students in the educational system, beginning with preschool and continuing through graduate studies at the university level. The stated goal was to improve the level of education for all students with the goal of creating "global citizens by opening up global horizons" (Ministry of Culture (Taiwan), 2011). To assist in the instruction, teachers from America were brought to Taiwan to provide native English speaking for the students (Ministry of Education, 2013a).

The MOE also devised a curriculum plan that clearly delineated the strategies and guidelines for developing curriculum, as well as expanding the opportunities for teacher training. In 2001, the Nine Year Integrated Curriculum for Elementary and Junior High Schools began with a trial run, but was officially implemented in 2004. Language arts, which includes English, Mandarin, Taiwanese, and some local languages, is stated as consuming 20 to 30 percent of the class time (Clark, 2010).

Because education is of great importance to Asians, the schools are considered the main source of essential academic content to help students to become more intelligent and skillful. The pattern of education has been for the instruction to be teacher-led discussion, with the students absorbing the information so they will be able to perform well on the exams. In the English classes, the emphasis is placed on reading and writing because the assessment can be determined through an exam. The teachers are required to complete the textbook in the allotted time, so there is not much discretionary time to do extra activities in the classroom. This teaching method was observed in both public and private schools, with the teacher modeling the language for the students (So., n.d.). With the changes encouraged in Taiwan's English 
education, the students are able to read the texts but cannot produce the language in an authentic fashion (Lee, 2011). The directive given by the government is encouraging a different approach in teaching by encouraging more student focused activities to provide a social setting for the students to practice the language (Chang, 2011).

This new focus on including English in the Language Arts program has been met with mixed responses. Because reforms that are implemented in education can result in social reform, the cultural impact can result in challenges to ways of thinking and the traditional values in the society. Taiwan's educational system originally was founded on the ideas and concepts of Confucius. There has been more emphasis on learning theory for the educated class, while the lower class focused on learning practical skills. When the new design in education was introduced, it included a more well-rounded curriculum where the subjects were comprehensive and interconnected for the entire spectrum of the student population (Ministry of Education, 2007).

This curriculum change has met with a variety of responses in Taiwan. Concern was expressed that the English language could impact Taiwan's national identity (Enever, Moon, and Raman, 2009, Chang, 2004), and could result in the loss of local culture and languages. In the same study, the results showed that many agreed that Taiwan would be more competitive on a global platform if the level of English language proficiency improved. More than half of the people in the study realized that the benefits outweighed the negative aspects, admitting that English was an avenue for national as well as individual growth (Lin, 2012). In other research with parents, the findings showed that even though the parents encouraged English instruction at an early age, they did not want to see that Mandarin Chinese instruction discarded, and were concerned about creating a burden for their children in having to learn another language (Chang, 
2008). Some criticism of the new policy reflected a concern that students may value the western culture and give up their Taiwanese cultural identity if they learn English with foreign English teachers at a young age (Wang, 2009).

\section{Teaching Methods}

While looking at the literature on effective teaching methods to use with young learners of English, it was discovered that it included a wide variety of very effective methods. The teaching of English is multi-faceted, and because of the varied instructional methods for teaching English, different types of research on those methods will be noted.

One of the top goals of the Taiwan MOE (1999) is to promote communicative language for the students. The goal is to provide instruction to students so they can communicate in the target language in different situations. Using the language in a contextual setting that is meaningful is the main purpose of this instruction, which includes the four dimensions of language learning; listening, speaking, reading, and writing. Chang (2011) indicated that the dimensions of language need to be taught as integrated skills to help build students' abilities in communicating. A positive result of using this method is that it provides an environment that is conducive to success in acquiring a new language through a setting that allows students to progress with less anxiety-producing activities by making the content comprehensible. The instructional setting is a way for students to develop their language while learning social skills with their classmates as they work toward becoming more proficient in the language. This research was conducted with some secondary level students rather than elementary level (Chang, 2011).

An underlying theory (Bozorgian, 2012) is that better listeners and speakers will make better readers and writers; hence, the emphasis on listening and speaking. This gives rise to yet 
another advantage of the audio-lingual method. Teachers stress the importance of proper pronunciation, with special attention focused on intonation. The audio-lingual method takes the audio part (listening) and puts an emphasis on a response from the lingual part (speaking). Much of the instruction at the elementary level in a second language requires the students to listen to the new vocabulary and then repeat what was said or sung. No specific studies on this method of instruction were found for elementary students. In one study that was with university students by Abu-Melhim (2009), some of the positive results were that the students could learn correct intonations by following the example of the speaker. With correct pronunciation and grammar modeled by the instructors, it also decreased the number of errors the students would make in their speech. The research also found that the students could become more familiar with conversations in the target language and respond more like native speakers with this method. The main benefit is that students get plenty of opportunity to listen and understand before they speak, which builds up their confidence so they can speak with fewer errors in both grammar and in pronunciation.

Research was compiled on a variety of effective listening studies, with a focus on a more interactive approach. Findings in one research project (Sevik, 2012) stated that listening is the first step in learning a new language. The use of songs was the method used to provide a safe environment for the students to listen and repeat, while being actively involved in the music. Listening was the beginning activity, but was followed up with other activities that involved speaking, reading, and writing.

Phonemes and phonics are an integral part of instruction, especially for young learners who are learning the language. Phonemes refer to the sounds the letters make individually or together with other letters. The progress in reading ability is integrally connected with the 
students' ability to differentiate the phonemes. A study conducted with English language learners in the United States focused on the importance of a continued focus on introducing and reviewing the different phonemes. Phoneme instruction produced positive growth even in the students who were in the second grades and above (Szabo, 2010). Phonics was another method listed as the foundation for learning English (So, n.d., Martinez, 2011). The basis for the research by So (n.d.) was that students would be better able to master English if they are trained in phonics first. When students are taught the sounds and combinations correctly, they will be equipped to read all the combinations of sounds. The author also stressed that in the teaching of phonics, vocabulary must be taught in context. While teaching phonics to students, it is important to have them use all four dimensions of language acquisition and that instruction can begin together in a balanced presentation. This research supports the view that in teaching the four dimensions, it should be centered around the instruction of phonics. The results of this research support the idea that a good foundation in phonics can provide resources to attain any level of English that the learner desires (So, n.d.). The focus population in the research by Martinez (2011) was EFL (English as a Foreign Language) students. There was improvement in determining the sounds of the letters and the students' reading comprehension as evidenced by the students who had correct pronunciation and better understanding of what they were reading. Because of the exceptions in the English language, phonics instruction did not improve the students' spelling, however. The phonics instruction showed significant gains mostly in reading comprehension.

Chang, Chang, \& Hsu (2010) conducted a study on teaching writing as early as first grade. Based on the goals of the MOE to support listening and speaking, this research focused on including opportunities for first grade students to do some authentic writing, as opposed to 
just copying words, for ten minutes each day. The results found that there was measurable success in the students' language development by incorporating instruction in writing at an early age for EFL students (Chang, Chang, \& Hsu, 2010). Writing was also found to improve when coupled with explicit phonics instruction (Martinez, 2011).

Mukoroli (2011) stated that the foundation for producing and comprehending the English language is impossible without vocabulary. Some vocabulary instruction is more useful for basic communication, but to assist students to achieve a deeper understanding of academic content, it is essential for instruction to include content vocabulary. Even though the English language can be daunting for lower level English language learners, teachers are encouraged to include higher level vocabulary to provide resources for students to reach their grade level requirements (Mukoroli, 2011). Memorizing can also be used to teach vocabulary, but research by Yek (2006) found that the usual method of memorizing vocabulary lists did not result in ability to communicate better. Rather than just memorizing, more innovative methods to enhance students" vocabulary acquisition could result in greater ability to use the language (Yek, 2006). Min (2008) combined reading and vocabulary to assist in the process of vocabulary retention. The research found that students who used this method performed better than those just receiving reading instruction. Through the use of intensive vocabulary exercises, the students could retain the vocabulary for a longer period of time than they could by reading exercises alone (Min, 2008).

Research by Sheu (2008) examined teaching methods that employed using English story books rather than just the textbooks. This method found that through the use of storytelling, students could begin to understand some content words that were in the text, as well as provide usable sentence patterns. Stories would provide a way to access prior knowledge in a more 
natural and meaningful context. Teachers in the study noted that illustrations provided opportunities for the use of language to provide insights into understanding a broader base of English (Sheu, 2008). When examining the reading level of the English storybooks by Chang (n.d.), it was found that the intended age level of the storybooks was much younger than the learners in Taiwan, but the simple rhythm and rhyme included in those storybooks proved to be a valuable tool in teaching English, regardless of the students' age (Chang, n.d.).

Goldenberg (2008) stated that the preferred method of reading instruction was in the primary language first to provide a foundation for the children to scaffold the second language learning. As teachers introduce learning tasks, explanation can assist in language transfer for younger learners. Even as students progress, it is necessary for instruction to include continued introduction of academic vocabulary and content in the primary language. Information must be provided at a level for students to adequately access, but there also needs to be ample opportunities for students to practice the new content language learning (Goldenberg, 2008). That principle has also been supported by Cummins (1999) where he states that basic communication and academic vocabulary must be taught together to provide a good foundation in the new target language. Other research conducted in Taiwan involved instruction of reading strategies. This study looked at ways of implementing reading strategies such as prediction, linking to prior knowledge, vocabulary instruction, and questioning. The students made progress but it took a long time to see improvement. (Shen \& Huang, 2007).

Kim (2010) looked at using questions to provide steps for students' learning. The questions were used to help students to look at their own way of thinking, and to help them in organizing their work in the class. Teachers asked questions to guide students to access the instruction. The coaching questions helped with classroom atmosphere as students worked 
towards becoming more of a community. Other questions were intended to extend the student understanding of the language in an environment that provided positive support to them.

Questions that extended what students already knew were used to facilitate and guide learners in their interaction. Teachers also used collaborating questions to encourage the students to share from their personal experiences (Kim, 2010). A study conducted by Motlhaka (2012) found that the classroom must have a positive atmosphere to generate more feedback from the students. The study examined providing topics of interest to the students, using questions, and the use of cooperative learning as methods that produced growth in students' ability to listen and understand (Motlhaka, 2012).

Part of the traditions of many cultures includes working together in groups. Using that tradition in classes where English is being taught has been very beneficial. In the model of differentiated instruction for English language learners (Rothenberg, 2007), reference is made to the issue of having different levels or the same academic levels in the groups. Although the research (Slavin, 2010) shows that placing the students in groups is an effective way to improve the academic growth of students, the most effective way to do that is to have heterogeneous groups. His research does not deal solely with the teaching of English but in a variety of subject areas. Rather than adding more instructional methods, Slavin encourages teachers to use it in a complementary way with the successful methods they are already implementing in the classroom. Specifically addressing the needs and instructional methods for students learning the English language, Rothenberg supports the heterogeneous grouping model because it allows for the lower achievers to have the model and example of higher achievers, as well as the important part of being a part of a social group where they are able to progress in a safe environment. The 
only exception to the heterogeneous grouping is when the instructor is doing some intense instruction with a specific focus that lends itself to a specific academic and proficiency level.

A study was conducted on the use of the bilingual environmental print (BEP) that is found on many school campuses throughout Taiwan by Yeh and Teng (2010). Posted on stairs and other visible places around the campus are sentences and phrases in both Chinese and English. In this study, the BEP was incorporated into some of the lessons by two English teachers providing opportunities for the students to speak. After the introduction and review of a selected group of sentences, students would be given an oral assessment to determine if they could speak them correctly and understand what they meant. The results found that to make BEP be more effective it needed to be designed from the bottom up with students being more involved in the design and usage. (Yeh and Teng, 2010).

A study that strongly influenced this researcher's instruction was conducted by Echevarria, Vogt, and Short (2004), and was called the SIOP (Sheltered Instruction Observation Protocol) model. In the school district where this researcher taught in the States, this research was studied and the results were implemented specifically into the ESOL classes. Although the research was done in the United States with students who are in English speaking schools rather than in a foreign country, many of the concepts and principles of instruction can be applied to the English as a Foreign Language (EFL) classroom because these techniques are effective teaching methods. This study included observing the impact of different types of instruction, but looked very closely at the method of sheltered instruction. The researched approach is described as one that builds on 'language support services' to make the English language more accessible to the students, utilizing the basic English vocabulary and grammar that is necessary for students to master, while including academic, or content vocabulary that students must be able to 
understand. The research also examined how the socio-cultural classroom used social interaction and integrated language usage in context as a means to scaffold instruction to assist students in accessing the English language. The research noted how teachers could maintain the same educational objectives for students, while at the same time including language objectives as a means of assessing whether students have understood what is being taught through the use of a variety of assessment tools. Features of the SIOP method include an emphasis on the preparation of the lesson, scaffolding, using different types of groups, integrating language processes of listening, speaking, reading, and writing, how students would apply what they had learned, and then how to assess their learning. An important aspect of this model includes what is called 'comprehensible input', which refers to using speech that is understandable by the students based on their proficiency level. Supplementary material, such as visuals, realia, or technology, is also an important resource for this model to assist in the instruction. Rather than adding more tasks on already busy teachers, this model provides an effective method for making the English language accessible to students through successful methods observed in the research that are already happening in the classroom, and making adjustments to them to include the aspects of this research.

\section{Challenges for Teachers}

There were some consistent themes that were discussed regarding the challenges that English teachers face, not only in Taiwan, but globally (Enever and Moon, 2009). In many of the articles, challenges were discussed that affect the teacher's effectiveness in teaching English which included teacher training and situations observed in the classrooms.

Large class size, limited instructional time, lack of consistent resources, and demands from a variety of sources were some of the challenges described by many researchers (Hsieh, 
2011; Chiang, 2003; Enever \& Moon, 2010; Chern, 2010; Chang, n.d.). In addition to those issues, some teachers mentioned demands from parents and administration (Hsieh, 2011). Lack of support and sufficient resources were cited additionally in regards to the school setting, along with the teachers questioning their own teaching abilities (Chiang, 2003; Her, 2007). Other findings included cramped classrooms with few resources (Enever \& Moon, 2010). The wide range of language ability was also listed in the challenges (Chern, 2010; Chang, n.d.; Nunan, 2003, Garton, Copland, \& Burns 2011). Observing the use of bilingual environmental print, some of the teachers felt the "words and phrases of the BEP were too difficult and not useful" (Yeh \& Teng, 2010).

Because equity of educational access is becoming more of an issue due to mandated English instruction in schools, the concern is disparity in students' English language level as a result of private school instruction (Chang, 2008). 'Cram schools' are private schools that operate in afternoons, evenings, and weekends that have been selected by parents for their children that have resulted in widening the gap in students' language abilities (Her, 2007). The increased ability of students from 'cram schools' also creates challenging teaching conditions for English teachers in the elementary school (Garton, Copland, \& Burns, 2011) and has even been noted as widening the gap between students in urban and rural elementary schools (Chang, 2004).

Additional research showed areas that created difficulties for the teachers. Many teachers felt their training was not adequate to prepare them to teach English well (Min, 2008, Enever, Moon, \& Raman, 2009, Her, 2007). In that research, questions were raised about what level of proficiency was necessary in order for teachers to be effective in primary schools, with results finding that teacher's lack of confidence was a greater issue (Garton, Copland \& Burns, 
2011). Teachers noted that their ability to produce the language was much lower than their receptive ability. This same research noted that private schools hired native English speakers who often times were not qualified teachers, which was a detriment to the education of the children in those schools (Chang, 2008).

\section{Conclusion}

Taiwan is a country that values the education of their students. The government has implemented English instruction in the hope of creating more global citizens. Most of that has been accepted positively, but some concern has been that the culture of Taiwan could be lost at the expense of learning the English language. After looking at different instructional methods for teaching English, it is evident that there are too many effective methods to isolate only one. Many challenges were observed which were affecting teachers' ability to accomplish the goals of teaching the language. No research studies were found that had been conducted with private schools in Taiwan with the goal of making a comparison with public schools. The main concern observed was that private schools created a wider range of language levels in students that the public school teachers were required to teach. 


\section{Chapter 3 - Methodology}

\section{Proposed Methodology}

To achieve some of the additional suggestions from the literature review, the research conducted in this study used a qualitative approach involving interviews with public and private school teachers. The research focuses on the instructional methods used in the local classroom that are the most effective in improving students' abilities to listen and speak in English. A comparison between the public schools and the private schools was made to see what the differences are in methods, outcomes, and the challenges the teachers face.

In reviewing the literature, a comparative study between the instructional methods used by the teachers in the public and private schools was not found. This study takes a look at the differences and similarities of instruction in both of those settings. As Taiwan students who were not willing to speak the target language were observed, the question arose about what was actually going on in classes to see if they were indeed learning the language. If that was so, how could efforts of the government be enhanced by using ideas from local teachers to improve outcomes of their emphasis on English language learning?

The growing body of literature dealing with teaching young learners will serve as background for the study. In the study by Garton, Copland, and Burns (2011), they suggested examining how local English teachers from around the world function on a daily basis in the classroom and how their challenges and methods can impact the teaching of English globally. The same suggestion was made by Wang (2008) to study how individual teachers have been implementing the English instruction on a local basis. Hsieh (2011) proposed a comparison of English learning by observing different instructional methods with young learners. Chen and Tsai (2012) found that the majority of research had been conducted on 
college and adult students, but suggested that research on primary and secondary school levels could result in a more unified framework on which to monitor and define English education in Taiwan. Nikolov encouraged more classroom research for early language learners, but stated that there was a lack of research about what is effective with different age groups while learning English (Nikolov, 2009). That research and additional research by Her (2007) also suggested studying the training, proficiency, and professional knowledge of English teachers. Most of the questions used in this research came from these different research findings from the literature review. As teachers were observed during the period of time this researcher spent in Taiwan, additional questions emerged that would need to be answered to clarify information they were sharing.

\section{Rationale for the Study}

This study is a qualitative research project to help ask some questions that give teachers an opportunity to share their ideas, thoughts, and methodology in their instruction. Qualitative research provides a tool to understand the stories of particular individuals (Guion, Flowers, Diehl, \& McDonald, 2011). Qualitative research provides a means to ask open-ended questions that can be used in designing some revisions to methods applied to the teaching of English. In this research, questions and answers from the interviews could be used to identify some needs that are common to English instruction on the local level that might influence policy decisions on a local or even a national level. These methods can also be used to observe some success stories in the different classrooms on an individual level.

The type of methodology that will be used is a particularistic case study method (Merriam, 1998). This research actually looks at a number of different teachers and their successes and challenges in local classrooms where they teach. This case study looks at local 
teachers as they describe their own personal instructional methods and experiences, which include their successes and their challenges. A look at questions about the phenomena of not speaking in English is from a local teacher's perspective. This research design can offer more indepth information than other methods. One of the objections to the case study research design is that it is not generalizable. Because this study is describing specific situations in the local setting, the research is particularistic. Looking at the questions at hand from the perspective of teachers who are actually working with students provides a more holistic view of the situation (Merriam, 1998).

The research conducted in this study used a qualitative research approach involving a short questionnaire survey and then individual interviews with public and private school teachers. The semi-structured interviews (Patton, 1990) are a general interview guided approach to allow participants to answer the same questions in the same sequence. Interviews were conducted on a one-to-one basis to allow teachers to express their opinions without the influence of inferred responses from other interviewees or research questionnaires. The individual interviews also allowed for all the questions to be answered, which facilitated the comparison of the responses.

All of the interviews were set up based on the convenience of each teacher. Most of them were conducted in a quiet setting in the school building, or in a private residence. One, however, had to be conducted in a public setting, which was a restaurant. When we arrived for the interview, it was quiet with not many people in the restaurant and we were able to procure a table away from most of the noise of the business. There were a couple times in the transcript that it was difficult to understand what was being said because of some of the background noise coupled with the heavy accent of the teacher. 
The questions focus on their pedagogical methods used in the classroom that produce the desired result of the students speaking English, the teacher's ideas pertaining to their training, and their suggestions on ways to improve students' speaking and listening abilities in English, both locally and nationally. The length of each interview was from approximately fifteen minutes up to thirty minutes, determined by the speaking ability of the interviewee. The responses were not very in-depth even though the questions had been given in advance so they could think through their answers.

\section{Population of the Study}

The participants were selected based on their willingness to assist in the research through the interviews and are all currently involved in education in Taiwan. Each participant is either a public or private school English teacher of young learners. Each of these teachers can speak three languages, with English being their second or third language learned. The questions for the survey and the interview questions were given to each participant in advance so they could read through prior to the interview. Because their first language is not English, their responses would be more limited during the interviews if they had not had time to think through their desired responses to each question.

\section{Sample}

The sampling of teachers was composed following the quota sampling method to include the approximate percentages of the genders of elementary teachers of English. There were eight teachers in this project, with two of them being private school teachers, and the others were public school English teachers. They teach in local settings in Taiwan, either in public or private schools. In a study done about the education in the Asian region (Morris, 2000), the gender comparison of teachers showed percentages in America's elementary schools in 1987-88 school 
year of $12.4 \%$ males and $87.6 \%$ females. In the same book, percentages in Taiwan's elementary schools in 1993 had 39\% males and 61\% females. In keeping with the general percentage of gender in the teaching profession, a male was included with seven females.

\section{Procedure}

After compiling the list of questions for the survey and the interviews, a copy was provided to each participant to give them time to read through each one, to look up unfamiliar words, or to ask for additional explanation of what the questions meant. A letter of invitation to participate in and an explanation of the research was given to each person. The first survey question inquires about their first language. When the question was originally designed, it asked what their first language was, and then what other ones they could speak. After receiving some responses with only one choice circled, the question was rewritten for them answer it again. It was not clear that the question was a two-part question.

To give some examples of different types of teaching methods, examples had been placed in parenthesis. Some of the teachers just expounded on each one, rather than describing examples of regular teaching methods in their own classroom. All of the interviews were conducted in English (see Appendix B for the interview questions). Because this researcher does not have a grasp of the Chinese (Mandarin) language, communication in Mandarin with the participants was impossible. The teachers' limitations in English impacted the short responses, because they might have been more thorough if they had been able to respond in Mandarin. This researcher conducted all of the interviews with the teachers. Each of the teachers either had worked together with the researcher in the classroom, or had met through the educational system in the county where we were all instructors. All of them were pleased to participate in the research, but some were nervous when thinking of being interviewed. 
The data collected from the interviews were recorded, transcribed, coded, and analyzed for themes. The transcriptions of the interviews were cross-checked with the interviewees to verify and validate their reliability. After contacting each teacher, three transcripts were received in return with some revisions. The revisions were to the grammar and spelling of the words, without any changes in the content of the response. Two teachers said that they were satisfied with the transcript as it was. The others did not respond, but the original instructions stated they only needed to respond if some things needed to be changed. In this research and reporting the results of this study, measures were taken to ensure the confidentiality of each participant. Any reference made to an individual teacher does not have any identifiable information to provide anonymity for each participant.

An attempt was made to implement software designed for qualitative analysis called HyperRESEARCH 3.5.2. Because the sample population is small, this researcher was able to employ the coding and compile a list of codes. One of the benefits of using a small sampling for a qualitative research project is that there can be a greater differentiation of the codes, clearer definitions, and an easier way to identify the codes. The drawback is that there can be too many codes, which is what transpired the first time the transcripts were coded. A second review of the transcripts took on more comparison and contrast between the methods being used in the public and private schools without the use of the software. Themes that went along with the questions emerged providing a way to divide the input from the interviews into more usable sections.

The approach used in data analysis was the constant-comparative method followed by coding the data into categories based on the research questions and theories that had been noted in the literature review. The results from the questionnaire were compiled and then the interview transcripts were analyzed to discover recurring themes in the responses from the teachers. 
Responses were sorted from the public and private school teachers to begin comparison based on instructional procedures to compare and contrast the results. When data showed a consensus in the instructional methods of the teachers, those became themes discussed in the thesis. To maintain the validity in this research, stages of analysis were followed as described by Johnson (1997). Beginning the work as a 'detective', cause and effect was examined for the findings and responses from the teachers. In analyzing the data, low inference descriptors were used to provide responses using what teachers said in their interviews. Triangulation of methods was used in comparing what had originally been observed with the teacher interviews and then literature review findings to interpret the data. Research findings were shared with some peers, both uninvolved in this line of research as well as ones who might have some experiential insight into this research. Careful examination was focused on negative case sampling in responses that were not expected or were different from what was originally anticipated. While analyzing the data, the goal was to maintain reflexivity by being aware of this researcher's own influences on the research process and the influences of others involved in the process.

Limitations exist in the external validity of this study because of the experiences of the local teachers being unique to just the small sampling in this research. Because this research is limited in size and due to the personal experience of the teachers, it would be difficult to make a generalization for all of the elementary school settings and teachers in Taiwan. The purpose of this research was not to make generalized suggestions, but rather to present insight from the local teachers themselves. Patton (1987) said that qualitative methods are ideally suited to local situations because it looks at the "local conditions, needs and interests". Because of that, the methods to study implementation of these ideas need to be "open-ended, discovery oriented, and capable of describing developmental processes and program change." The perspective and 
insights of the local teachers will serve as a way for many to understand the effective instructional methods as well as the challenges the teachers must overcome, both in the public and private educational setting. 


\section{Chapter 4 - Research Findings}

\section{Introduction}

After teaching ESOL in a midwestern state in America for six years, the researcher had an opportunity to teach English overseas through a special program of the Ministry of Education in Taiwan. From the first year of teaching in Taiwan, an observation was made that people rarely initiate English conversation. Many seemed shy, or perhaps afraid to speak to a foreigner. One person who was studying to obtain a $\mathrm{PhD}$ in English would only speak through a translator. That person was never heard to speak the English language at all. Thinking of the time and effort that had been expended in Taiwan's educational system to increase the opportunities for students to increase their knowledge of the English language, it was surprising to see the small number of those students who would speak. The seeds for the research had germinated long before the opportunity was presented to do some research on what was happening in some of those classrooms in the country of Taiwan.

The intent of the proposed study was to investigate the teaching of English at the local elementary level from both public and private school teachers' perspectives, including their teaching methods and outcomes, and what challenges they face. The dual focus was on local teachers' methods used in their school setting and the outcome of their instruction followed by a comparison of the two school settings.

The following questions were the basis for the research: (a) What instructional methods used in the second language classroom are effective in increasing the receptive and productive dimensions of English for young learners? and (b) Do private schools have different methods, outcomes, and challenges than public schools? 
To find the answers to those questions, a small survey was given to the eight teachers in the sampling to find out their educational background and their self-assessment of their English level of acquisition (see Appendix A for a compilation of answers to the survey). That was followed by semi-structured interviews with each teacher individually (see Appendix $\mathrm{C}$ for a list of interview responses). During the interviews, the instructors shared some of the different types of instructional methods used in the classrooms and whether they felt their training adequately equipped them to teach their students to listen and speak English. The interviews also included questions about the challenges they were facing and what suggestions they might have to improve English instruction. The research findings in this chapter are based on analysis of the following: surveys, semi-structured interviews, and observations while teaching during this research.

\section{Background}

The participants in this study were eight English instructors in a small agricultural city in Taiwan. They ranged in age from thirty to sixty. There were seven females and one male. Six of the teachers were working in a public elementary instructional setting and two were teaching in a private English school. Five of the public school teachers had earned a Master's degree, and one had earned a bachelor's. The summer following the interviews, one of the teachers completed her doctorate degree from a university in Taiwan. Of the two private school teachers, one had a Master's degree, and the other had a bachelor's degree, and had also earned a TESOL endorsement from a university in the United States. Both of the private school teachers had pursued a degree in the English language. Two of the public school teachers had a degree in the English language, and one had English literature included in the English language studies. The other majors were translating, finance, education, administration, and business. The two private 
school teachers received their degrees from universities in Taiwan. Three of the public school teachers received their degrees from Taiwan, and three from overseas.

Taiwan requires a primary teaching certificate to teach in an elementary school. A primary English teaching certificate can be obtained by teachers who want to teach the English language. Some of the public school teachers had both certificates. Three had the primary certificate, and four had the primary English certificate. One private school teacher did not have a teaching certificate, but the other private instructor had both. In every elementary school, there is always at least one full time English teacher, but the remaining teachers are considered substitute teachers, even though they teach in the school all year long. Their contract is renewed on a yearly basis, so they potentially could be moved from school to school each year. Three of the teachers in the public schools were in the substitute teacher category.

The number of classes public school teachers were assigned ranged from less than ten to more than twenty classes per week. One of the private school teachers had five to ten classes, and the other had twelve classes per week that each lasted for two hours. When asked if they prepared lesson plans, four of the public teachers said they did, and two did not. The private school teachers both prepared lesson plans. In the public school setting, teachers just made plans for themselves, with the exception of preparing a year long plan to present to the Director of Student Affairs and the Principal in the first semester. Most of the public school teachers taught one to three grade levels twice a week. The private schools had English classes through the sixth grade, with one starting in second grade, the other in third grade. The class size ranged from less than 15 up to 20 students per class. In the public schools, the class size ranges from 20 to 35 students per class. Each class in the public school is forty minutes long, and they have two sessions of English per week with the English instructor, with the exception of first grade only 
getting one class per week. Each campus had English posted around the school, such as on the walls and on the stairs. Both public and private schools used that in their instruction.

All of the instructors agreed that students should receive English instruction early in elementary school. The grade agreed on unanimously by the public school teachers was first grade. The private school teachers said that second or third grades should be the lowest grade for English instruction.

The first language of each instructor was something other than English. Most of the public school teachers learned Mandarin as their first language, with the exception of one who learned Taiwanese. One private school teacher spoke Mandarin first, and the other spoke Taiwanese. They all currently speak three languages: Mandarin, Taiwanese, and English. In the schools, the language of instruction is mainly Mandarin.

When asked to do a self-assessment of their English proficiency, the public school teachers ranged from intermediate to advanced in all four aspects of the language; which are listening, speaking, reading, and writing. A public school teacher was very well aware of deficiencies in pronunciation, although the knowledge base of the language was very good. One of the private school teachers rated her level as proficient in all four aspects of the language. The other placed her level as between intermediate and advanced.

One of the goals of the Ministry of Education in Taiwan is to produce students who can communicate in English. When asked if their students were able to communicate in English, the teachers all said that their students could communicate mainly within the setting of the classroom only. Through the use of phonics or guided practice, the students would be able to respond to the questions and be able to communicate with the teachers or fellow classmates. A private school teacher noted that for the beginning students, she uses bilingual instruction to build a foundation 
for the acquisition of the new language. Instruction that was observed by the researcher in the public school classrooms saw many of the teachers using bilingual instruction to build on the previous knowledge of the students.

\section{Study Findings}

Three themes emerged from this study:

Theme 1: What instructional methods are being used effectively by the participants to enhance the speaking and listening ability of the students learning English?

Theme 2: What challenges do the participants face in accomplishing the goal of English acquisition for their students?

Theme 3: What do the instructors in this study perceive as improvements to the teaching of English to produce the desired results?

The listing of the themes is in a question form because it facilitated the description of the responses by the instructors (see Appendix B for interview questions). Although the themes are listed separately, there is considerable overlap between them. Frequently the participants' responses overlapped more than one theme. The responses will be discussed where they apply most logically. Each theme will be discussed first from the perspective of public school teachers, followed by that of the private school instructors (see Appendix C for a list of teacher's responses in the interviews).

Theme 1: What instructional methods are being used effectively by the participants to enhance the speaking and listening ability of the students learning English?

This section discusses the interview responses from the teachers regarding the pedagogical methods used in their classes. It also looks at which ones they considered to be 
most effective in increasing the students' speaking and listening abilities in accessing the English language.

Public school teachers. When asked about the methods used in the classroom, some participants described the methods that had been listed in the question for examples, some talked about specific methods they had found effective, and some gave examples of specific incidents in the classroom. This section is a narrative report of their responses on those areas. Because the first language of each of these teachers was not English, some of the responses were not grammatically correct. When including quotes, some minor revisions were made to improve the flow of the words without affecting the meaning that was being presented by the teachers.

In general, the participants included the methods that were given as examples in the interview question. The interview question was "What teaching methods do you use in class how do you teach?" The examples provided were TPR, music, role play, storytelling, "listen and repeat" (audio-lingual method), language learning in context, and other. In the public setting, the teachers were required to complete the textbook curriculum in a given school year, which resulted in planning and instruction that was provided by just following the teacher's guide. It did not require much planning at all, except to confirm that they would finish each unit in time for quarterly exams. When asked if they made lesson plans, four public school teachers said they did, but only for themselves. They did not have to give plans to the principal or directors. A public school instructor mentioned that she did a year long "big picture" lesson plan at the beginning of the school year for the English classes which was presented along with the lead teachers for each grade level to the director of student affairs and the principal. 
In describing the methods used in their classrooms, all of the teachers included TPR (total physical response) and "listen and repeat". "Listen and repeat" was used while including scaffolding to build the students' understanding and learning of the language. A public teacher who teaches the younger grades enhanced "listen and repeat" so it did not get boring. She said, "I like to use song or chant or games to let kids practice, and to ask them to do some repetition." With the younger students, music was used extensively in the classes where the researcher co-taught with this instructor.

Another public school instructor incorporated role play in her classes as part of a game where "one of them will be the interviewer or the reporter, and the other ones answer the questions." In her classes, it was observed that the use of games required students to be engaged in listening and speaking English words from the unit they had studied. In other classes it was observed by the researcher that games were being played, but there was not really any incorporation of language speaking practice in the game.

For learning in context, another instructor described how maps were used to teach specific vocabulary in context. He said:

"If I teach maps, I will teach direction or teach the city. For example, a unit might be about directions of the streets. When I teach this kind of unit, I will bring out a real map of the school. I will ask them where the school is. In the center of the city? I change the direction, so they really see those places. I let them practice. If it is meaningful, that would be better."

In addition to the methods that were given as examples, many of the teachers mentioned or modeled other specific instructional methods they used in their classes. The idea of cooperative learning was addressed by each of the public school instructors in a heterogeneous 
setting. Cooperative learning was stated to be a good method to teach different levels of students. For example, when they work together, they can "help each other to speak in English and finish their homework or workbooks." It was also expressed that "teamwork is a good way to encourage the higher to help the slower". In addition, a teacher described how she would provide opportunities for success for the higher and lower English level students.

She stated, "If I explain the text in class, I will ask a second question. If the answer is 'yes' or 'no' for the lower level student, then they can answer. Then I will ask the higher level students to explain the answer to force them to speak more English and to demonstrate if they can understand the whole lesson."

A different teacher referred to the involvement of all the students, regardless of their level. They explained that "in a group, it is safe for peer practice in small groups". Cooperative learning was also used while teaching new words to another group of students. To practice speaking, the teacher had students repeat words after her. Later they read the new words to their team leader. Another way they work as a group is during a game in which they use English to interview each other or survey other students.

Other methods that were expressed individually by the teachers showed some very creative uses of the resources that the teachers had. In one case, a teacher described how she would scaffold her lessons to enhance the understanding of her students. She said, "Sometimes I teach conversation after key words. I teach key words in the first step, then phrases, and then the basic conversation. I let them role play with it. So, step by step." When teaching the remedial class, it was also noticed that the students understood what she was teaching, but could not formulate the answers in English. She said, "I give them options. For example, I say, 'I will 
give you three options - first one is basketball, number two is baseball, and number three is dodge ball.' When they cannot say it fluently, they just copy my pronunciation."

Two of the public school teachers mentioned the use of phonics in their classrooms. One of them talked about using phonics to help students read by using the basic phonics rules. The other recounted that phonics had been an effective instructional method. The teacher said, "Phonics rules are very important. In every class, when we learn new words, I always use phonics rules to introduce the word. For the students who are at a better level, it's a review. But for some lower level students, it is very important. That is the way they can have a chance to memorize the word. Only when they have the basics in phonics can they build on their own phonics rules and start to learn words and how to say them. I think this is the most important for the young learners."

Two other public school instructors talked about using realia in the classroom to teach vocabulary and culture. The first one said:

"I use some toy I bought, or for example a banana, a hamburger, or I use some boxes. After I eat in McDonald's, I just take the hamburger boxes and show them the boxes." The second teacher said, "Every semester we teach them in a very active way. This semester, we connected American baseball to their food culture, to make students learn English in a fun way, to make them like learning English.”

That was a reference to a unit in which the students viewed some pictures of baseball, hot dogs, cars, and apple pies. The students were shown how to prepare a hot dog, and then could eat them while watching a short video of highlights from American baseball games.

Many of the teachers mentioned that writing was not a very big part of their instruction, if it was even present at all. The writing activities that were described were mostly just copying 
words or sentences. One exception was how small white boards were used for students to write their answer as a form of informal assessment in class. When they played games, she had them write the answers rather than speaking it aloud.

"The master learning method" was described by one teacher who used that method with cooperative groups. "I ask students to practice some words, and if they can't memorize those words, I will teach them again and ask them to repeat and practice. Then I will check whether they can say it. If they can't, I will teach them again and ask them to practice. Sometimes I ask students who can recognize those words to teach other students who still cannot. They work cooperatively, so the higher- ability students teach lower-ability students. When we give them enough time and practice, most students can learn well."

Some of the teachers described ways their elementary schools encouraged students to speak English more. One school had a program called Daily English. Each semester, the teachers came up with a workbook with conversations that were appropriate for each grade level. The first grade book started with simple chants. The sixth grade started with a simple dialogue between two people. The students reviewed the conversations during several class sessions. They had to say it to another student who was designated as the Teacher's Assistant, as well as to their teachers or parents. One morning a week, the students had to say the dialogue to the English teachers who would stamp their little booklet with their signature. Even though the students may not have understood every word (or any word), they heard them over and over again, and were required to speak because Daily English was part of their grade.

In the second semester, this school also had a weekly conversation that was introduced to the entire school body by the foreign English teacher and one of the Taiwan teachers. As the 
foreign English teacher, the researcher would say the conversation in English, and then it would be explained in Mandarin so the students could understand what was being said. Then the students repeated it several times to practice the words. They would earn points in their class for saying it to the English teacher.

A different public school had an English corner. A token system had been developed to reward good behavior or some other task to earn the tokens. The instructor said, "The students could use the tokens as real money to buy food or little cookies. They have to use simple English." The school also had a foreign teacher, provided by the parents' association, who taught an extra class, giving opportunity for the students to listen to a native English speaker. The homeroom teacher was the helper in the class.

An additional public school provided the only exception to extra English emphasis. The English instructor said it was left up to the English teachers to decide what methods they would use. She chose to teach basic classroom English. She said, "I noticed that my students will say the classroom English which I commonly say in my class. They didn't realize they were speaking English. They were just mimicking what I said and so they learned English unconsciously."

While teaching in that classroom, she suggested a time for each student to be able to speak with the foreign English teacher in an authentic conversation. At the end of each class, three or four students would come to a circle in the classroom and fill out a form about themselves that included their name, age, grade, and birthdate. Because Taiwanese students are able to read English, that gave the students opportunity for instant success in understanding the form. They then read their answers aloud, which would often provide evidence of the cooperative group effort as the students would help each other. Originally, they responded with 
trepidation, but it later turned into excitement when they knew they would be able to actually speak with the foreign teacher.

The methods that were cited as being the most effective in getting the students to listen and speak varied. Two instructors felt that building a foundation of phonics produced the best results. It was also stated that modeling the speech for the students through scaffolding had positive results. Another teacher felt that repetition of the language through the use of song and chants produced the desired objectives in students. It was observed by an instructor that the use of cooperative learning in class was the most beneficial in getting students to listen and speak. Classroom English was used on a regular basis in another classroom, and that instructor saw that students were speaking those words and phrases without difficulty; sometimes without even realizing they were speaking English. Storytelling was chosen as the best method by an additional instructor, but noted that just having the students speak more was the key.

Private school teachers. Both private school teachers said they used all of the methods that were listed as examples. One described how TPR (total physical response) was used in the class with younger children to teach classroom commands. She said that TPR makes it easier to teach verbs. She also described how role play could be used in the class when students needed to borrow school items, such as pencils or erasers, from classmates. She teaches how to ask for those items and respond to those questions. With "listen and repeat", she used a CD that features a native English speaker so the students can hear the intonation as well as the pronunciation while they learn to speak in English. When she was talking about teaching in context, the instructor referred to grammar rules that are different in Chinese than in English. As they proceed through the story, they would see the usage of those rules in the passage. 
The other private school teacher used role play in reading the story "The Ugly Duckling". She said, "I think that it is easier and it's fun for them to learn. They like to memorize all the sentences." For speaking practice, she encourages the students to talk in class. "For example, I will call on some of the students to answer if they don't open their mouths voluntarily. For the lower learners, I will give easier questions, but for the higher students, I will give harder questions."

Both of these teachers had some unique methods that they use in their classes. They each mentioned groups, but they had homogenous groups. It was explained that it was easier to teach students if they were placed in classes by their levels. The teacher expressed that her slower learners oftentimes do not want to learn, even though she uses the same methods. With the higher-level students who want to learn, they learn quickly and ask for more. The instructor places students in that school in leveled classrooms so each group can be exposed to instruction they can access. It was said of the higher students, "I ask them to memorize more so that they can learn deeply."

Memorization is used in instruction by both of the private school teachers. That method was employed in role play and in learning in context. The teacher modeled emotions in story telling so the students could demonstrate those feelings while speaking English more fluently. An observation by that instructor was that "later, they will feel it is easier. A better reader is a better writer. I think if they read more, they want to speak more, and they can write more. They can easily memorize many good sentences." When working on storytelling, the other teacher introduced the story one section at a time. In every class, they learned a small part of the story. After they had memorized the story completely, students were taught to tell the story 
using finger puppets, hand puppets, or masks. Every year, that private school has a storytelling competition with students acting out familiar tales and fables.

Private school students were encouraged to speak by asking them to talk more English to their classmates. From the beginning, classroom English is taught because they are to use only English in class. As students acquired the language, the instructor would model correct responses so the students could see how to speak accurately. The students then were able to use the phrase or sentence correctly in subsequent dialogues.

Real life experiences are a large part of the instruction at one of the private schools. The instructor would take students on a picnic, or to a restaurant to practice how to order a steak. They learned names of food items and learn how to use correct table manners. Students also engage in different sports so they can learn vocabulary for that sport. A trip to the supermarket provides opportunities to speak about food items or specific areas in the store.

A unique method in a private school setting was the spiral method. The teacher started instruction with students in the second grade, and often would teach them until they graduated from high school. The instructor said that teaching grammar, which is difficult to understand the first time it is introduced, is reinforced the next time it is taught. The students pick up the concept "correctly, slowly, gradually".

The other private instructor also uses only English in classroom instruction. Many classroom assignments were worksheets that the students were required to hand in. She sends lessons home with the students to review. In class, after a reading comprehension lesson, she will have the students choose the correct answer on a test.

One major difference between the private and public school teachers is the use of writing. Writing is used in one of the private schools and requires students to write words and 
phrases they learned in class (see Appendix D). When writing a friendly letter is the objective of the lesson, the students are given an example to use. For their homework, they can either respond to the letter or write a letter to a friend. The other teacher has a lesson about family members. Examples are provided that the students read together. For homework, they write about their own family by filling in blanks with information.

Storytelling and role play were chosen by one teacher as the most effective methods in developing speaking and listening, The other teacher felt that the spiral method provided the necessary learning so her students could listen and respond more effectively. She also said that the ability to correct her students in the context of their learning was an authentic way for them to build on their language acquisition. She used evaluation and assessment through the use of the KK (Kenyon and Knott) symbols, and phonics to assist students in becoming more independent learners as they acquired the language.

\section{Theme 2: What challenges do the participants face in accomplishing the goal of English acquisition for their students?}

Public school teachers. All of the public school teachers had other responsibilities besides teaching, which included administrative tasks. The teachers were responsible for the English department, and the substitute teachers had to assist in competitions for the whole semester. Remedial teaching was also assigned to some of the substitute English teachers. The main English instructor in a local school mentioned that she was the chief of registration in the school, but was compensated by a reduced load of classes.

In the public schools, each grade, except first, has only two class periods per week to teach English. First grade has only one hour per week. Four teachers stated that the time was not enough for the task. 
Two instructors noted that the different English levels presented a great challenge. Trying to model pronunciation was a big challenge for the teachers because as second language learners themselves, they still struggled with some English sounds. The Chinese language is based on different tones, whereas English is not. It was stated that learning how to place the tongue in the right position is important in producing the language. Explaining that concept and the intonation to the students was challenging. Because the elementary students are learning Mandarin as well as English, another said it could be confusing to them. Students were very shy as well, because they were afraid they would make a mistake and be laughed at by their friends or parents. That fear was cited as an influence on the students, resulting in a difficulty to convince them to speak English in their daily life on a regular basis.

Two other local public school instructors felt that motivation was a huge challenge for students who, not having a means to readily use their English, do not try to speak. One was concerned with how to get them interested in learning English. The other said that low motivation was causing classroom management issues in class.

Another large challenge was to explain words without visual aids. It took a lot of creativity for the teacher to adequately explain many concepts. The example given was the word "favorite".

"I say, for example, ‘you like apples, you like peaches, and you like strawberries. But, you like apples the best. Apples are number one. So, now you know what "favorite" means. If I say apples are my favorite, it means that apples are the number one in my heart. If I explain in English to them, it's more like they learn it on their own. It's not like I just give them the answer. They found the answer by themselves." 
Private school teachers. The challenges for the private school teachers included some that were the same as in the public school setting and some that were different. One of the challenges listed focused on teaching the class in English, because the teacher said that presenting vocabulary and concepts effectively for a lesson requires a large knowledge base of the English language. Three specific challenges were described by that instructor:

"First is that they do not want to come to my school because they don't want to learn. They come to my cram school because of their parents. So their motivation is not very good. Second, they don't have enough patience to sit for a long time. And the third is that some of them do not want to open their mouths to speak. They just feel shy and they are afraid of making a mistake.'

The other private school teacher described the most difficult challenge as "the life experiences they don't have. If we are teaching western food, some of the food they have never seen. Although we have a picture, it is difficult to understand what the food really tastes like, or is made of, like a tortilla."

The second challenge is asking for directions. She said that even with a map, they can not direct people to those places. "Even though they know how to say the different instructions on getting to a place, when it comes to the application part, they cannot really use it well in the situation."

Another challenge is that the students neither understand traditional holidays from Taiwan nor from the West. Students do not comprehend the meaning behind holidays. They care only about presents or costume parties. For traditional Taiwanese holidays, students do not know the origins either. The teacher stated that when Taiwanese holidays were taught, students did not know the origins or why they had traditional foods for holidays. The grammatical 
differences between Mandarin and English are also a great challenge in teaching. Explaining the usage of verbs such as 'lend' and 'borrow' is a difficulty because in Mandarin, they are the same. Some English verbs and nouns are the same word in Mandarin, and it is challenging to teach the differences to her students.

Theme 3: What do the instructors in this study perceive as improvements to the teaching of English to produce the desired results?

Public school teachers. The interview question asked what their suggestions were both locally and nationally. On a local level, most of them suggested more time and more opportunities for the students to speak. To do that, an English environment would need to be developed. Some referred to the English Village that was housed in one of the local elementary schools. It was made up of eight different themed classrooms: restaurant, airport, airplane cabin, bank, theater, museum, gym, and shopping mall. One morning a year, usually fourth to sixth grade students from every school in the county got to take part in classes and activities held in the Village, followed by lunch in the restaurant.

Oral exams were used in one of the public classes, and the teacher suggested that as a way to improve the students' speaking ability. An observation made was that the Taiwanese students care about their grades, so an exam has some built-in motivation for them to learn how to speak as they read the passage. An instructor that taught the higher elementary grades included an oral assessment for her class which was a recitation or reading of a passage from the textbook.

Using the resources that were available in the community was another teacher's proposal. She suggested using university students or people from local churches to assist in designing English activities during summer or winter vacation. For schools with foreign 
teachers, providing more time for students to speak with them would allow for some authentic communication, and help students overcome the fear of speaking. With the availability of foreign teachers, western cultures can be introduced in fun ways. Two instructors perceived speaking more with the foreign instructors as a benefit to students as they made career choices or looked at travel in the future.

Three instructors suggested that students watch more English television programs, listen to the radio, or read newspapers for a set time every day. Repeating the conversation while watching was a suggestion to give students more opportunities to speak. In addition, it was suggested that the students buy the CD published by the textbook companies to assist students with lessons they have in school. In the classrooms, two instructors felt their instruction would be improved if they had more technology tools such as Smartboards connected to the internet or a listening center set up for students.

Another suggestion was that the government should employ more long-term teachers. "Temporary English teachers are not familiar with the school environment and the students. The government should get the best teaching for the students. Long-term teachers will have better teaching methods."

On a national level, three of the instructors mentioned two other countries that provided English on a daily level both in the classrooms and in the environment. In both Singapore and Hong Kong, the textbooks and the instruction are in English.

More teacher training seminars was suggested by four of the six teachers as something that would be beneficial. It was mentioned additionally about having "workshops where teachers can share their experiences. The MOE can also introduce more foreign teachers which would be beneficial both locally and nationally." 
Private school teachers. The private school teachers had some of the same suggestions. Most of these suggestions involved the use of resources in public schools. They both agreed that more class time was necessary. They also thought that there needed to be an English environment where students would have time to create their own language usage. It was suggested that the students have opportunity to speak with foreign teachers for increased conversation practice. Both referred to the English Village at one of the elementary schools in their city. They felt that those classrooms prepare the students to use the vocabulary specific to that themed setting. One said the resource would be most beneficial if students could spend more time there "to develop more culture in real life, including how to greet teachers, how to greet parents in the morning, and how to dine in different ways. They can have more time to learn how to help with house chores or taking care of their lives." With more days in the Village, students could learn more about daily life and have more time to practice using their new vocabulary.

Using parents as a valuable resource for students by helping them use and review the flash cards at home was another proposition. An idea was to have students memorize more short stories, because of the emphasis on incorporating reading and speaking in the memorization method. In the public schools, she felt it would be beneficial for students to be placed in homogenous classes to provide opportunity for focused instruction.

Another idea was a school competition to improve speaking skills through setting specific days for each class to have a turn to speak.

"Like Monday, it would be grade two, and they would use English a lot. So for Monday, students and teachers are encouraged to speak English sentences. They can use it as a competition between classes to see which class uses more sentences with other teachers 
on campus or students in other grades. They would win the honor of speaking the most English.”

Along with that idea, online programs, such as MyET, were referred to that could be enlisted to provide additional practice for the students, including challenges and competitions. Once they finished the challenge, students would have a way to keep track of their progress. Each class would have a record kept by the teachers to compete against other classes. It could be used around campus for students to "challenge their own speaking, their pronunciation, and they would also have fun on the computer."

One of the survey questions was whether the school had English posted around the campus. Every school, both public and private, had English signs posted. One way to use those decorations would be to provide some fun competitions, while allowing the students to speak more.

"For fifth or sixth grades, they can have a list or a book with them to see how many sentences they can read no matter how long it takes. For some students, they may only need three months to finish all the sentences around campus. Other students may need two years. Teachers can help students read sentences correctly. That would encourage them to actually use the sentences on campus instead of seeing the sentences as decoration."

Another use of available resources was for students to read the daily announcements in English. Each school has time in the morning and at lunch that could be used for students to make announcements or use as a radio show.

"They can just recite or role play the conversation they have in their English books or the books they have around campus. Every student can take the challenge and volunteer to do 
the radio show. They can read aloud. That would be a good way for many students to practice their speaking. Other students can listen to the conversation again and again to become familiar with the situation."

A standard curriculum on a national level was suggested to be very beneficial in teaching English. That type of uniform curriculum would provide a set format that could be used to provide useable conversations while speaking with foreigners. The curriculum would include introducing the country, famous local foods, culture, or holidays. "Students would be able to communicate with foreigners in English instead of just learning sentences from a textbook or reading stories which would not be able to help them when they see foreigners who need help in their lives."

\section{Summary}

In this chapter, the findings were presented from the study of the teachers. These findings are based primarily on analysis of the surveys, the interview transcript, and observations throughout the time the researcher was in the classrooms with the teachers. Findings were discussed in three parts that correspond with the three major themes that emerged from the findings of my research. The findings are divided between the public and private school teachers.

Data in the first section focused on the instructional methods that were used in the classrooms of the sample teacher population. The second section focused on the challenges the teachers faced in trying to accomplish the goal of producing English-speaking students who were able to listen and understand. The third section asked for ways to improve English instruction at the local as well as at the national level. Because each teacher is an individual and the students are all unique to each setting, the findings were as varied as the ones found in the literature 
review. Because of that, it is difficult to evaluate the appropriateness of the methods, the impact of the challenges, and the suggestions for improvement. To that end, Chapter 5 discussed the themes that emerged from this research, and recommends future practice and research. 


\section{Chapter 5 - Discussion And Recommendations}

The purpose of this study is to examine methods used for teaching young English language learners in Taiwan. These classes are from first to sixth grade, both in the private and public school sectors. Research was conducted through a short survey, individual semistructured interviews, and observations from this researcher being in the classrooms as the foreign English teacher. This chapter reviews, analyzes, and discusses the relevant literature with the findings of this study. This chapter also outlines the implications of the findings for teachers of English to students of other languages and describes the impact of suggestions made by the local teachers, as well as a brief look at a historical master teacher.

\section{Discussion}

Two fundamental questions framed this research:

1. What instructional methods used in the classroom for teaching a second language are effective in increasing the receptive and productive dimension of English for young Taiwanese learners?

2. Do private schools in Taiwan have different methods, outcomes, and challenges than public schools?

The research questions were answered by themes that emerged from interview data. This data is reported in Chapter IV. The following themes emerged from this researcher's data.

\section{Theme 1: Effective Instructional Methods to Enhance Speaking and Listening Skills of}

Young English Language Learners. In looking at teaching English to young learners, the research stated that starting instruction early for the students took advantage of the optimal period of language learning (Chern, 2010). Starting early also provided a longer time to acquire a higher language proficiency and to provide more equity for all of the student population 
(Enever, Moon \& Raman, 2009). With a student population that is more proficient in the language, there would be greater opportunities for Taiwanese students to choose for their future (Lin, 2012).

With the literature agreeing that starting early is a benefit, this was substantiated by the findings of this study. Many children in Taiwan attend preschool and kindergartens where English is taught. If instruction does not begin until third or fifth grade, the children will lose any language skills they had learned at an earlier age. This researcher found that the private school teachers wanted to begin instruction in second or third grade with the reasoning that younger students could not sit still, or did not know classroom manners well. In Taiwan, the private schools are attended after the children have been in the regular classroom all day. This could be a reason that would possibly contribute to younger children not being able to sit still. Because education is important in Taiwan, parents do expect their children to attend private after-school classes to help them to achieve more, but that makes for a very long day for children.

Though the participating instructors did not have access to the research literature that was reviewed, the participants described all the different types of instructional methods that were found in the research with young learners. TPR (total physical response) along with rote "listen and repeat" were two examples that are used by all of the public school teachers.

Using cooperative groups in the classroom was included by each of the teachers. Including this type of cooperative group instruction in the Taiwanese classes is changing the face of education from teacher-led to more student directed learning. Some of the teachers were allowing the different language level students to provide a way for all students to be involved in the task. 
Differentiating instruction has been researched (Rothenberg, Fisher, 2007) for English language learners with methods that were described by some of the participants. Included in that research was scaffolding which builds on skills that have been previously introduced to help children grow to a new level of proficiency. The idea of scaffolding empowers students to complete tasks they could not previously do on their own. Teachers in both the public and private school classrooms implemented this method.

The differences between the public and private sectors show that the private school classes include smaller class size, focused English instruction with clarification in Mandarin, homogenous groupings, and writing assessments using authentic writing. With the smaller classes, the teachers are able to provide more one-on-one instruction while providing clarification when students do not understand. The leveled classes provided the setting for focused instruction, as well. This was because the students are able to access the instruction at the same level. The writing assessment is the most significant difference from the public schools. Three of the public school teachers mentioned using writing in their classes, but it was just fill-in-the-blanks or copying sentences. In the private schools, students are given opportunities in various classes to write about their own family or write something to their friends. Teachers require students to take what they have heard and read to produce an authentic written example of their language ability.

The research conducted by Chang (2011), states that:

“different from the grammar translation method focusing merely on reading skills, CLT (Communicative language teaching) considers four skills - listening, speaking, reading, and writing - as integrated skills, which should not be taught separately. CLT aims to develop students' communicative competence. To communicate effectively, the students 
are involved in different kinds of activities that require practicing various skills to understand their peers and make themselves understood by others. Further, CLT creates a non-threatening language environment that lowers the learners' anxiety and makes class input comprehensible. In the classroom where CLT is applied, the students can develop their language as well as social skills when they work together with their group members to achieve a common goal"' (p. 28,29).

In a study done by Chang, Chang, and Hsu (2010), the students did focused writing for ten minutes a day in a first grade class. Because not much research had been done with EFL (English as a Foreign Language) students that young, there was no comparison study, but this study gave "visible evidence for success in encouraging learning development" (p. 96).

Whether the students can communicate in English is an important part of this research. Based on the teachers' assessments of their classes, many of their students are able to communicate, at least with classroom English. The question here might be how to determine to what 'communicate' actually refers. The research done by McLaughlin (1992) found: "the requirements to communicate as a child are quite different from the requirements to communicate as an adult. The child's sentence constructions are shorter and simpler, and vocabulary is relatively small when compared with what is necessary for adults to speak at the same level of competence in a second language as they have achieved in their first language. The child does not have to learn as much to achieve competence in communicating as the adult does" (p. 4).

When looking at the process of learning a new language, the beginning stages of building a vocabulary and grammatical foundation require a substantial amount of time. Cummins (1980) stated that the students who had a good foundation in their first language manifested a higher rate 
of progress in second language acquisition because an academic foundation is already available to them (p. 184).

Learning a new language is influenced by many factors that affect students' ability to access the language. In this research project, those factors were not available to this research to confirm the findings in regard to students' ability to communicate in the English language. Therefore, these findings are based on the teachers' assessments of their students as reported in the interviews. Regardless how well they can communicate, the benefits of starting young can provide an advantage for students as they grow into later language learning stages (Nikolov, 2009).

Theme 2: Challenges Faced by Instructors in Reaching the Goal of English Acquisition for

the Students. The top three challenges listed by both public and private teachers included insufficient instructional time, getting students to speak, and having opportunities for them to speak. The greatest challenge for the public school teachers was the additional responsibilities they had in conjunction with teaching. Most of the students were assessed as being able to communicate with guided practice within the English classroom setting, but outside the classroom there were few opportunities for the students to use English. Even though there was a wide array of challenges as listed by all of the teachers, including the range of language ability, time, and training, they aligned with the findings in the literature review. Many of these challenges were observed in other research projects, not only in Taiwan, but in other countries where English is being taught to young children in the public schools (Hsieh, 2011; Chiang, 2003; Enever \& Moon, 2010; Chern, 2010; Chang, n.d.; Garton, Copeland, \& Burns, 2011.) One of the public school teachers talked about difficulty with pronunciation, of which that teacher was very well aware. There was concern about the impact on students in their ability 
to hear the correct pronunciation of the words. This challenge was cited in some of the research done by Nikolov (2009) where she states that teachers are non-native speakers of the target language and their proficiency level is below the native-like language speaker (p. 5).

There were two interesting challenges that were unique to this research. A private school teacher and a public school teacher mentioned the necessity to have a much broader vocabulary base in English in order to explain new concepts. These teachers are working with the older students who are at a higher academic level, therefore requiring higher academic instruction to provide steps to get to the next level on their own. One teacher explained that introducing a new concept to her students in a language that they understood allowed them to construct their own learning. These teachers were actively involved as facilitators in providing constructivist instruction that encouraged the students as they built their own learning and understanding.

Another surprising challenge was the inability of students to give or follow directions. In both the private and public schools, teachers mentioned lessons with maps and giving directions. One of them said that students were unable to give directions on how to get from one place to another. Another teacher lamented that students could not give directions on getting around the city. It was suggested that because of the ready availability of taxi drivers, students really had no need for giving or following directions.

\section{Theme 3: Improvements in Instruction of English as Suggested by English Instructors to} Enhance Students' Speaking and Listening Skills. The two suggestions made by all of the teachers were to have additional opportunities for the students to listen and speak, and to have more English environments, like the setting of the English Village at one of the schools. Those two suggestions build on each other and could be used to enhance the students' ability to communicate more. Even though schools throughout the county visit the Village every year, one 
recommendation was to increase the length of each stay to provide for more focused instructional time while the students are visiting. The Daily English that was provided by one of the public schools required the students to speak the conversation for that unit multiple times, after having practiced it in the classroom together. Those conversations were recorded as part of their English grade for the semester, which provided motivation for some of the students to practice speaking.

Many of the suggestions could be conducted with the resources that are currently available in the schools. Using the BEP (bilingual environmental print) posted around campus was a suggestion that would incorporate resources already available. The instructor proposed including it in daily announcements or setting up a grade level competition to see which class could use more of the English during a given time period. Research done on BEP reveals that it is much more effective when the activities are designed from the bottom up with students being more involved in the usage of those phrases and sentences (Yeh and Teng, 2010).

Another recommendation was the use of English majors from the local university or some people from the area churches to provide activities during winter or summer vacation for the students. They would have the resources available in the school setting and could plan activities that would extend students' English exposure.

Two public school instructors recommended that standard classroom equipment incorporate the latest technology. Many of the teachers described their resources as computer ebooks and CD's provided by the curriculum publishers. In Taiwan, teachers are very familiar with technology, but in the classroom it is not always readily available. That challenge was discussed by Chern (2010): "there is a need for more computer-mediated learning programs designed based on the ideas of communicative approach, the one advocated in the curriculum 
guidelines, and involve meaningful use of the English language. Programs that focus on practicing pronunciation and intonation, such as MyET, should also be developed to cater to the needs of young EFL learners.” (p. 2). When suggesting techniques for helping students to improve their English, a private school instructor also recommended.

A private school instructor suggested that parents become more involved by assisting their children with homework. From a public school instructor, it was mentioned that many of the parents are not able to be of assistance because they do not know the English language. Research noted that parents support the instruction of English (Chang, 2008), but that does not always mean that they can be of assistance. As an ESL (English as a Second Language) teacher in the United States before going to Taiwan, this researcher saw that with many students. If time or assistance was not provided in the classroom setting, they were not going to be able to complete their assignments.

There were five teachers who indicated the need for additional training in teaching English, along with time for teachers to share ideas with each other. This was a focus in research done by Wang (2008) and Her (2007). In the research done by Her (2007), concern was shown for the lack of teachers trained to teach a second language. In this study, only two of the public school teachers had studied English in the university. The concern expressed by teachers for the need for more training in effective second language teaching methods is valid.

One of the methods used by the public schools and two of the private school teachers was memorization. While admitting that memorization had not been incorporated into instruction, one of the instructors stated how effective it was for her to learn a new language by learning usable phrases and sentences while studying at the university. She said that memorization of useful dialog is helpful no matter what language a person is trying to learn. 
Two instructors proposed that the government hire more long-term English instructors rather than hiring substitutes. The turnover in instructors requires newly hired substitute teachers to learn the curriculum and the dynamics of a school every time they are repositioned in a different building. If the teachers were allowed to remain in the same building for a longer period of time, there would be more consistent instruction because they would be more familiar with the curriculum and the students for consecutive years.

Observations from Hong Kong and Singapore were referred to by three teachers, where instruction is conducted in English in the public schools, and where the environment has more English available on a daily basis. Their suggestion was a national directive to incorporate more English in students' daily environment through increased English instruction and curriculum beginning at an early age. For the population at large, the suggestion would also include more English language on signage and in public places so that students would be exposed to it on a regular basis. As a visiting foreigner in Taiwan, this researcher saw an improvement in the environmental English from the first visit to the second. Travel around the island was possible, even though the researcher was not able to read or speak Mandarin, because of the increase in English on signage provided by the public transportation department.

Six of the eight teachers recommended more interaction with foreigners. The MOE has been working toward that goal by providing more foreign teachers to rural areas where foreigners are less likely to visit. In areas where this researcher lived, there were very few foreigners. That limits the ability of students to have meaningful interaction with them. The suggestion of using CDs with foreign speakers would at least allow students to hear the language being spoken with a natural flow and intonation. Other suggestions to listen, read, and watch English media would assist in that as well. 
Another proposal included a national standard curriculum to be developed to provide students with language so they could speak about themselves, their local foods, and the country's culture. That would give a standardized curriculum on a national level and provide a common format to prepare them to communicate with English speakers.

From the findings of this research, the result that was foremost to this researcher was that the practice of the participants aligns with the research that has been done, both in Taiwan and globally. Implications can be made that new teaching methods are being introduced such as cooperative groups to develop more student led learning. The suggestions of the local instructors could be beneficial in many Asian countries where English is being introduced in the lower grades in primary schools. Providing opportunities for students to practice speaking and listening on a daily basis in the classroom will build a strong foundation of English language proficiency.

\section{Teaching Methods of a Master Teacher}

The dream of teaching overseas began to be realized by this researcher with the opportunity to teach students who had come to the school in the United States from different countries. This researcher was an ESOL (English for Speakers of Other Languages) facilitator in a public elementary school. The school offered training in the effective instructional methods on a continuing basis to provide ready access to the language. The methods adopted in the school district were some of the same instructional methods described as effective in interviews with teachers in Taiwan. Instructors who did not have specific language teaching training were still using some of the best practices based on research.

While contemplating master teachers, the first who came to mind was Jesus. Whether or not a person believes what He said, it cannot be denied that He was an effective teacher. Jesus 
did not have academic titles behind His name, but He taught with authority. He did not limit His teaching to only one kind of classroom, but because of His sincere desire for a relationship with His students, He taught people of every socioeconomic level as well as people from different cultures and backgrounds. Jesus implemented constructivist instruction, allowing the students to build their learning from what He presented. He employed instruction that allowed for participatory learning from the students.

In an article in which Keller (1998) described Jesus' methods, some could be applied in this context. The first was that Jesus "met the people where they are . . . at their developmental level" (p. 36). The second method involved using information and examples from daily life. The idea of change was the third purpose of His teaching. Lastly, the author points out that Jesus is centered on God as His authority. When teaching a new language, we must be aware of our students' developmental level and present lessons that they can access and build on by using their background knowledge. The methods described by some of the instructors in this project employed real places and objects to give the students opportunities to use what they had learned in the context of specific settings. In language learning, if students do not make progress, the instructor needs to assess the methods that are not working and research others that might be effective. Because God is the Creator and Designer of all the languages, we can be confident that the strategies described in the Bible can be used as examples for us as language instructors.

Since English is considered a language of business and advancement, the need for qualified teachers is crucial. TESOL (Teachers of English to Speakers of Other Languages) has become very popular in many countries, and is a field of study that is being made available in universities across the world. Missionaries have traditionally been leaders in international development. Using TESOL in education from primary to tertiary levels, missionaries have 
equipped instructors to teach students of other languages using effective strategies and methods. Through the avenue of English instruction, many people have been able to travel abroad to teach English on almost every continent implementing the instructional methods from the Master Teacher.

\section{Strengths of the Study}

This study focused on interviews with some local English teachers, both public and private, about their instructional methods and some of their challenges. In a study done by Garton, Copeland, and Burns (2011), this same idea was suggested to compare what is actually happening in classrooms around the world. To that end, this research project presented insights from some local teachers in Taiwan.

The majority of research has been conducted on secondary or tertiary levels to observe and measure implementation of English instruction. Hsieh (2011) suggested more research with young learners. Along that same line, Chen and Tsai (2012) proposed that research spanning the grades would provide a more unified framework to monitor and define English instruction in Taiwan. Nikolov's research (2009) dealing with young learners stated that more research could be done on what is most effective for different age groups. This research project provided some examples of different types of instruction that are currently being implemented in classrooms on a local level.

The research done by Her (2007) had some unanswered questions regarding the available training and the proficiency of the English language instructors. Some questions included whether the teachers had received any training in the teaching and learning of English, how much they understood the directive to teach communicative English, and how they rated themselves in English language proficiency. Several of the responses from the sample 
population in this study paralleled the findings in that research, even though the research by Her was conducted in a university setting.

Although teachers in this study were from small local schools, the interviews provided a venue in which they could safely express some of the challenges in their teaching. The things they mentioned aligned with research as was defined earlier in this chapter (Hsieh, 2011; Chiang, 2003; Enever \& Moon, 2010; Chern, 2010; Chang, n.d.). Even though sufficient training was listed as a challenge, from observations in the classrooms, the teachers were using the resources they had readily available to them to compensate for their challenges.

In the search for studies done with private school teachers, very few were found that were conducted with that demographic. No comparisons were found that had been conducted with the public and private school teachers. This research provides a beginning step in a comparison of the methods used by the private schools and the public schools.

This study can be used as an encouragement to the MOE, the local administrators, and the teachers to see that progress is being made in providing quality English instruction for the students in Taiwan. The local teachers in this study all stated that their students are able to communicate in English, although most of it is with guided practice within the parameters of classroom English. That practice is foundational and provides tools for the students to begin to speak more outside the classroom. The methods described could be used as examples for other teachers to employ in their classrooms.

\section{Limitations of the Study}

The participants in this study were all local Taiwanese teachers who were not native English speakers. Because of their limited English, their interview responses were not as in- 
depth as they might have been had they had been able to express their thoughts in Mandarin, and then have them translated into English.

Because there was no standardized way to measure the effectiveness of their instruction, the results were based on the subjective observation of the teachers. The interviews provided teachers an opportunity to describe what they thought was effective in producing more language usage from their students. Not having a specific measure to determine the 'communication level' of their students left the determination up to the instructors.

The sample size is a very small representation of the body of instructors of English in Taiwan. The results could be generalized to settings where the demographics are similar. The participants in this study were involved in schools that had a strong desire and focus to provide quality instruction in English for the students. The private school teachers were from two of the top private English schools in that area. This setting limits the external validity of the study, but it does provide characteristics that are meaningful, coming from those who are involved in that instruction on a daily basis.

\section{Recommendations for Future Research}

Qualitative research has achieved the best results when new research produces follow-up studies (Firmin, 2006). That builds the external validity through research that parallels the study. Further studies on instruction for young learners of English could answer some of the questions that Nikolov (2009) presented, which included concerns about continuity of instruction into secondary classrooms, teacher proficiency, and appropriate instructional methods. Conducting similar studies in other schools throughout Taiwan in a variety of urban or rural settings is recommended. A comparable study in other cultures where English is being taught would provide a worthwhile comparison with this study. More qualitative research that involves 
public and private teaching methods that follow this research would provide a larger database that could be used in teacher training or as support by administrators for their local instructors. Strategies that are unique to private schools could be researched to see if they are potentially viable in the public setting.

As the use of authentic writing activities is unique to the private schools, research on programs that include focused instruction in writing could provide ideas that might be implemented in the local classrooms. With English being most effectively accessed when all four language aspects are included in instruction, research into how to incorporate writing instruction would provide some answers on how to do that.

Research on the challenges could be a basis for brainstorming what can be done to minimize those challenges. Perhaps administrators or education departments could visit with some of the local teachers to see what is being done to address those challenges for the benefit of the students and teachers.

One of the limitations of this study is that there was no way to measure the teachers' effectiveness, because it was based only on their observations. Finding a way to measure effectiveness for English teachers' instruction could be the basis for another research project that would help determine what methods are the best practices.

The suggestions from the local teachers on how to improve the teaching of English in Taiwan were valid propositions. Perhaps more research could look at suggestions to present the most benefit by using what is already accessible. Vast resources of money, time, and effort have gone into English instruction in Taiwan, but more studies like this might provide a more accurate assessment of what is being accomplished in the classrooms in Taiwan, and may be applicable in other areas globally. 


\section{References}

Abu-Melhim, A. (2009). Re-evaluating the effectiveness of the audio-lingual method in teaching English to speakers of other languages. International Forum of Teaching and Studies, 5(2), 39-45. Retrieved from http://0-ehis.ebscohost.com.library.cedarville. edu/eds/pdfviewer/pdfviewer?sid=a1503431-9a1f-4fcf-9109-c9ffb2f6bd77\%40 sessionmgr $98 \&$ vid $=43 \&$ hid $=4210$

Bozorgian, H. (2012). Listening skill requires a further look into second/foreign language learning. International Scholarly Research Network ISRN Education, 2012, 1-10. doi:10.5402/2012/810129

Chang, M. (2011, July). EFL teachers' attitudes toward communicative language: Teaching in Taiwanese college. Asian EFL Journal Professional Teaching Articles, 53, 17-34. Retrieved from http://www.asian-efl-journal.com/PTA/Volume-53-mc.pdf

Chang, F., Chang, S., \& Hsu, H. (2010). Emergent writing in Taiwan's grade-one EFL classes. Taiwan Journal of TESOL, 7(1), 67-100. Retrieved from http://140.119.172.17/journal/ ESL/index.htm

Chang, J. (2004). Ideologies of English teaching and learning in Taiwan. Retrieved from http://www.languageonthemove.com/wp-content/uploads/2012/05/ Chang_Jackie_ideologies-of-english-teaching-and-learning-in-taiwan.pdf

Chang, J. (n.d.) Role of Children's Literature in the Teaching of English to Young Learners in Taiwan. Retrieved from http://www.asian-efl- journal.com/Thesis_Chang.pdf Chang, Y. (2008, December). Parents' Attitudes toward the English Education Policy in Taiwan. Asia Pacific Education Review, 9(4), 423-435. Retrieved from http://www.eric.ed.gov/ PDFS/EJ835211.pdf 
Chen, S. (2005). Cooperative learning, multiple intelligences, and proficiency: Application in College English Language Teaching and Learning. Retrieved from http://dlibrary.acu.edu.au/digitaltheses/public/adt-acuvp120.25102006/01front.pdf

Chen, S. \& Tsai, Y. (2012). Research on English teaching and learning: Taiwan (2004-2009). Language Teaching, 45(2), 180-201. doi:10.1017/S0261444811000577. Retrieved from http://dx.doi.org/10.1017/S0261444811000577

Chern C. (2010) An overview of English language education at primary level in Taiwan. Retrieved from http://www.gavo.t.u-tokyo.ac.jp/L2WS2010/papers/L2WS2010_S-03.pdf

Chiang, H.L. (2003) EFL teachers' beliefs and practices at an exemplary Taiwanese elementary school. Retrieved from http://repositories.lib.utexas.edu/bitstream/handle/2152/497/ chianghl036.pdf? sequence $=2$

Clark, N. (2010, May). Education in Taiwan. World Education News and Reviews. Retrieved from file:///H:/Thesis\%20ideas/Thesis\%20ideas/WENR,\%20 May\%202010\% 20\%20Feature.htm

Cummins, J. (1980, June). The Cross-Lingual Dimensions of Language Proficiency: Implications for Bilingual Education and the Optimal Age. TESOL Quarterly, 14(2), 175-187. Retrieved from http://www.jstor.org/stable/3586312

Cummins, J. (1999). BICS and CALP: Clarifying the Distinction. Retrieved from http://files.eric.ed.gov/fulltext/ED438551.pdf

Echevarria, J., Vogt, M., \& Short, D. J., (2004). Making content comprehensible for English learners: The SIOP model (2 ${ }^{\text {nd }}$ ed.). Boston: Allyn \& Bacon.

Enever, J., Moon, J., \& Raman, U. (2009). Young learner English language policy and implementation: International perspectives. Retrieved from http://englishagenda. 
britishcouncil.org/sites/ec/files/books-young-learner-english-language-policy-andimplementation.pdf

Enever, J. \& Moon, J. (2010). A global revolution? Teaching English at primary school. Retrieved from http://www.teachingenglish.org.uk/ sites/teacheng/files/ Moon\%20BC\%20paper.pdf

Firmin, M.W. (2006). External validity in qualitative research. In, Ethnographic and qualitative research in education: Volume 2. (pp. 17-22). Newcastle, UK: Cambridge Scholars Press. Retrieved from http://www.cambridgescholars.com/download/sample/58709

Garton, S., Copland, F., \& Burns, A. (2011). Investigating global practices in teaching English to young learners. Retrieved from http://www.teachingenglish.org.uk/sites/ teacheng/files/ B094\%20FINAL\%20Aston\%20U niversity\%20A4\%20report_2column_V3.pdf

Goldenberg, C. (2008, Summer). Teaching English language learners what the research doesand does not-say. American Educator, 32(2), 8-44, Retrieved from http://www.aft.org/pdfs/americaneducator/summer2008/goldenberg.pdf

Guion, L., Flowers, L., Diehl, D. \& McDonald, D. (2011) Using Qualitative Research in Planning and Evaluating Extension Programs. University of Florida IFAS Extension. Retrieved from http://edis.ifas.ufl.edu/fy392

Her, J. (2007) .The globalization of English: Its impact on English language education in the tertiary education sector in Taiwan. Retrieved from http://www.asian-efljournal.com/Thesis_Jia_Huey_Her.pdf

Hsieh, M. F. (2011). Learning English as a foreign language in Taiwan: Students' experiences and beyond. Language Awareness. 20(3), 255-270. DOI: 0.1080/09658416.2011.573856. Retrieved from http://ehis.ebscohost.com.proxy.ohiolink.edu:9099/ehost/pdfviewer/ 
pdfviewer?sid=27deef91-fa42-4e42-a7dc-aef8eaf622a4\%40sessionmgr114\& vid $=5 \&$ hid $=104$

Johnson, R.B. (1997, Winter). Examining the validity structure of qualitative research. Education, 118(2), 282-292. Retrieved from http://www.dralessandro.com/subpages/ PDFfiles/Validity\%20Structure.pdf

Keller, M. N. (1998, Spring). Jesus the teacher. Journal of Research on Christian Education. 7(1), 19-36. Retrieved from http://0-eds.a.ebscohost.com.library.cedarville.edu/ eds/detail?vid=14\&sid=2f90d144-8929-475a-a1d7-32eb04452b17@ sessionmgr4003 \&hid=4202\&bdata=JnNpdGU9ZWRzLWxpdmU=\#db=reh\&AN=ATLA0000910864

Kim, Y. (2010). Scaffolding through questions in upper elementary ELL learning. Literacy Teaching and Learning, 15(1,2), 109-137. Retrieved from http://readingrecovery.org/ images/pdfs/Journals/ LTL/LTL_Vol15_No1-2- 2010/LTL_15.1-2-Kim.pdf

Lee, J. (2011, June). Moving Towards a More Balanced English Teaching: A Case from Taiwanese EFL Classrooms. English Language Teaching, 4(2), 132-137. Retrieved from http://www.ccsenet.org/journal/index.php/elt/article/view/10780/7627

Lin, Han-Yi. (2012, September). Local responses to global English: Perceptions of English in Taiwan. English Today. 28(3), 67-72. DOI: 10.1017/S0266078412000119. Retrieved from http://journals.ohiolink.edu/ejc/article.cgi?issn=02660784\& issue=v28i0003 \&article=67_lrtgepoeit

Martinez, A. (2011). Explicit and Differentiated Phonics Instruction as a Tool to Improve Literacy Skills for Children Learning English as a Foreign Language. GiST: Education and Learning Research Journal, 2011(5), 25-49. Issn 1692-5777. Retrieved from http://gisteducation.weebly.com/uploads/7/9/2/8/7928165/explicit_and_differentiated_ph 
onics_instruction_as_a_tool_to_improve_literacy_skills_for_children_learning_english_a s_a_foreign_language.pdf

McLaughlin, B. (1992) Myths and misconceptions about second language learning: What every teacher needs to unlearn. Retrieved from http://people.stfx.ca/ibernard/French\% 20Cohort/Les\%20rapports\%20de\%20la\%20table\%20ronde\%20corrigés/Collette\%20Gra ves-Smith\%20Myths\%20and\%20misconceptions.pdf

Merriam, S.B. (1998). Qualitative research and case study applications in education. (pp. xiii, 30). San Francisco, California: John Wiley \& Sons. Retrieved from http://www.amazon.com/Qualitative-Research-Study-Applications-Educationebook/dp/B001PTHYHM

Min, H. (2008, March). EFL vocabulary acquisition and retention: Reading plus vocabulary enhancement. Language Learning, 58(1), 73-115. Retrieved from http://ehis.ebscohost.com.proxy.ohiolink.edu:9099/ehost/pdfviewer/pdfviewer?vid=15\&s id=27deef91-fa42-4e42-a7dc-aef8eaf622a4\%40sessionmgr114\&hid=15

Ministry of Culture (Taiwan), Council for Cultural Affairs, (2011). [Education Reform].

Retrieved from file: ///H:/Thesis\%20ideas/Thesis\%20ideas/Education\%20Reform\%20\%20\%E5\%8F\%B0\%E7\%81\%A3\%E5\%A4\%A7\%E7\%99\%BE\%E7\%A7\%91\%E5\%85\% A8\%E6\%9B\%B8\%20Encyclopedia\%20of\%20Taiwan.htm

Ministry of Education (Taiwan). (1999). [The Ministry of Education 1999 Progress Report]. Retrieved on March 1, 2013 from http://english.moe.gov.tw/ct.asp? $\mathrm{xItem}=14597 \& \operatorname{ctNode}=11435 \& \mathrm{mp}=1$

Ministry of Education (Taiwan). (2004). Lu, M. [The $13^{\text {th }}$ international symposium \& book fair on English teaching]. Retrieved from http://english.moe.gov.tw/ct.asp?xItem=1192\& 


$$
\text { ctNode }=369 \& \mathrm{mp}=1
$$

Ministry of Education (Taiwan). (2007, March). [Taiwan's educational reform and the future of Taiwan]. Retrieved from file:///H:/Thesis\%20ideas/Thesis\%20ideas/Taiwan's\% 20Educational\%20Reform\%20and\%20the\%20Future\%20of\%20Taiwan.htm

Ministry of Education (Taiwan). (2013a). [Foreign English Teachers in Taiwan]. Retrieved March 1, 2013 from http://fetit.eng.ntnu.edu.tw/

Ministry of Education (Taiwan). (2013b) [General Guidelines of Grade 1-9 Curriculum of Elementary and Junior High School Education]. Retrieved from www.fhjh.tp.edu.tw/ eng_www/G1-9\%20curriculum.doc

Morris, P., \& Williamson, J.(Ed.) (2000). Teacher education in the Asia-pacific region: A comparative study. (pp. 230, 248). New York, NY. Falmer Press. Retrieved from http://www.amazon.com/dp/0815318561/ref=rdr_ext_tmb

Motlhaka, H. (2012). Developing ESL listening: Promoting student motivation. Retrieved from http://dspace.iup.edu/bitstream/handle/2069/756/Hlaviso\%20Albert\%20Motlhaka.pdf?se quence $=1$

Mukoroli, J. (2011). Effective vocabulary teaching strategies for the English for academic purposes ESL classroom. Retrieved from http://digitalcollections.sit.edu/ ipp_collection/501/

Nikolov, M. (2009). The Age Factor and Early Language Learning. In The age factor in context. Retrieved from http://books.google.com.tw/books?id=fkSkzZjTRcQC\& pg=PA19\&lpg=PA19\& dq=the+age+factor + in + context $+2009 \&$ source $=$ bl \& ots=P1QhoCPzSk\&sig=ZS7y_hXXn-u8irWz678GqHusjfs\&hl=en\&sa=X\&ei= 1pFSUe6dB8eikgXBjIGICQ\&redir_esc=y\#v=onepage \&q=the\%20age $\%$ 
20factor\%20in\%20context $\% 202009 \& f=$ false

Nunan, D. (2003, Winter). The impact of English as a global language on educational policies and practices in the Asia-Pacific region. TESOL Quarterly, 37(4), 589-613. URL: http://www.jstor.org/stable/3588214. Accessed: 29/03/2013.

Patton, M. (1987). How to Use Qualitative Methods in Evaluation. (2 $2^{\text {nd }}$ ed.) Newbury Park, CA: Sage.

Patton, M. (1990)). Qualitative research and evaluation methods. ( ${ }^{\text {rd }}$ ed.) Thousand Oaks, CA: Sage.

Rothenberg, C., Fisher, D. (2007). Teaching English language learners: A differentiated approach. pp. 87,88. Upper Saddle River, New Jersey. Pearson Education, Ind.

Sevik, M. (2012). Teaching listening skills to young learners through "Listen and Do" songs. English Teaching Forum, 2012(3), 10-17. Retrieved from http://americanenglish.state.gov/files/ae/resource_files/50_3_3_sevik.pdf

Shen, M. \& Huang, Y. (2007). Collaborative Action Research for Reading Strategy Instruction: A Case in Taiwan. Electronic Journal of Foreign Language Teaching, 4(1), 108-121. Retrieved from http://e-flt.nus.edu.sg/v4n12007/shen.pdf

Sheu, H. (2008, January). The value of English picture story books. ELT Journal, 62(1), 47-55. doi:10.1093/elt/ccm077. Retrieved from http://eltj.oxfordjournals.org/ content/62/1/47.abstract

Slavin, R. E. (2010). Co-operative learning: what makes groupwork work? In Dumont, H; Istance, D.; \& Benavides, F. (Eds.), The Nature of Learning: Using Research to Inspire Practice (pp. 161-178). Paris: OECD. Retrieved from http://www.successforall.org/ SuccessForAll/media/PDFs/CL—What-Makes-Groupwork-work.pdf 
So, G. (n.d.) Phonics for Chinese EFL learners. Retrieved from http://usat.ms/static/media/ cms_page_media/10/ENG064Phonics_for_EFL_Chinese_Learners.pdf

Szabo, S. (2010). Older children need phonemic awareness instruction, too. TESOL Journal, 1(1), 130-141. Retrieved from http://journals.ohiolink.edu/ejc/pdf.cgi/ SZABO_SUSAN.pdf?issn=10567941\&issue=v01i0001\&article=130_ocnpait

Wang, S. (2009). A qualitative study of English as a foreign language learning (EFL) by rural Taiwanese students with Christian native-English-speaking teachers. Retrieved from http://dspace.iup.edu/bitstream/handle/2069/193/Shu-Chuang\%20Wang\% 20Corrected.pdf?sequence $=1$

Wang, W. (2008) Teaching English to Young Learners in Taiwan: Issues Relating to Teaching, Teacher Education, Teaching Materials and Teacher Perspectives. Retrieved from http://www.asian-efl-journal.com/Thesis/Thesis-Wang.pdf

Yeh, C. \& Teng, C. (2010). The effectiveness of bilingual environmental print in an elementary school: A case study. Taiwan Journal of TESOL, 7(2), 45-75. Retrieved from http://140.119.172.17/journal/ESL/index.htm

Yek, S. (2006). Memory enhancing learning strategy instruction. Retrieved from http://ethesys.lib.mcu.edu.tw/ETD-db/ETD-search/getfile?URN=etd-0804106215407\&filename=etd-0804106-215407.pdf 


\section{Appendix A}

\section{Compilation of Teachers' Survey Answers}

Note: Initials are the first letters of teachers' names. The highlights are the private school teachers.

1. First language: $\quad$ Taiwanese $\quad 1 \quad 1 \mathrm{M} \quad$ Mandarin $\quad 5 \quad 1 \mathrm{D}$

What other languages can you speak?

Mandarin 8

Taiwanese 8

English $\quad 8$

2. Gender: $\quad$ Male $1 \quad$ Female 52
3. Age:
$31-40 \quad 4$
$41-50 \quad 2 \quad 1 D$

$51-60 \quad 1 \mathrm{M}$

4. Current teaching position:

Public elementary school 6

Private English tutoring center 2

5. Qualifications to teach: degree, major, institution, country, primary teacher certificate,

Degree: Bachelor's $11 \mathrm{M} \quad$ Master's $\quad 5$ 1D

Doctorat

Other - TESL, UCLA Extension (in

addition to Bachelor's M)

University: $\quad$ Taiwan 32 Overseas 3

Field/s of study: $\quad$ English language $\quad 2 \quad 2 \quad$ /literature $\quad 1$

Other: Translating Finance Education Business

Administration 
Teaching qualifications: $\quad$ Primary teaching certificate 3 1D G,P,K, M - None Primary English teaching certificate 4 1D P,E,C,M

6. How many English classes do you teach per week?

Between 5 and 10 (1) (1M)

Between 10 and $15 \quad$ (2) $1 \mathrm{D}(12$ classes $\mathrm{x} 2 \mathrm{hrs})$

Between 15 and 20 (2) More than 20 (1)

7. Do you design lesson plans each week? $\begin{array}{lllll} & \text { Yes } & 6 & \text { No } & 2\end{array}$

Who do you submit your lesson plans to?

Director of Student Affairs, Principal (County - year plan)

Other_- self 42

8. Taiwan elementary students should learn English.

Do you agree with that? $\quad$ Yes $8 \quad$ No

If so, when: Grade $1 \quad$ (6) Grade $2 \quad$ (1D) Grade 3 (1M)

9. What grades to you teach?

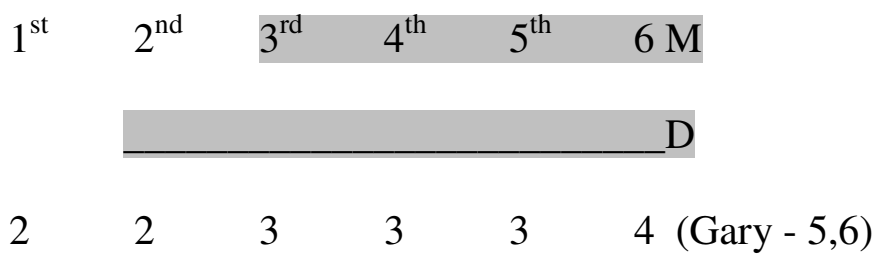

10. What is the average class size?

Less than 15 (1M) $\quad 15-20 \quad$ (1D) $\quad 21-25 \quad$ (1) $\quad 26-30 \quad$ (4) $\quad 30-35 \quad$ (1)

11. Does your school have English posted around the campus, such as on the walls and stairs?

$$
\text { Yes } 8 \quad \text { No }
$$


If so, do you ever use that in your teaching? $\quad$ Yes $\quad 8 \quad$ No

12. What kinds of assessment do you use?

Multiple choice $51 \mathrm{M} \quad$ Fill in the blank $42 \quad$ Oral 52

Listening 52 Writing $4 \quad 2$

13. Please rate your English proficiency in each category:

\begin{tabular}{|c|l|l|l|l|}
\hline Reading & Writing & Listening & Speaking & Overall \\
\hline I (2) A (4) (M) & I (4) (M I/A) A (2) & I (2) A (4) (M) & I (4) A (2) (M) P (D) & I (4) (M I/A) \\
P (D) & P (D) & P (D) & & A (2) P (D) \\
\hline
\end{tabular}

Proficiency Scale

Beginner - Limited understanding of English in communication.

Beginning to demonstrate receptive understanding and then produce a response.

Early Intermediate - Can understand short conversations on familiar topics.

Is beginning to respond more easily to a variety of communication tasks.

Intermediate - Able to understand and be understood in many social settings.

May still need support with higher level English.

Advanced - Can understand in a variety of contexts, able to use current English ability to learn in other academic areas.

Proficient - Can communicate with daily words and phrases as well as new topics without difficulty to a variety of audiences. 


\section{Appendix B}

Interview Questions

1. Could you please expand on the answer you gave for question eight about teaching English to young learners?

Why did you choose the specific grade level to begin the English instruction?

2. What other responsibilities to you have at your school besides teaching?

3. What teaching methods to you use in class - how do you teach?

(example: TPR, music, role play, storytelling, listen and repeat (audio-lingual method), language learning in context, other)

4. Do you include listening, speaking, reading, and writing activities in your lessons?

Can you provide some examples?

5. Can your students communicate in English? Please explain your answer.

6. What teaching resources do you have available, and what do you use?

7. Have you been given ideas on teaching students with differing levels of English proficiency? If yes, please explain.

8. How is teaching English effectively different than teaching other subjects, or is it different?

9. What teaching methods does your school implement to emphasize English language learning to the students?

10. Do you feel like your training and resources are adequate to teach English to students?

Please explain.

11. What methods have worked well for you in improving students' acquisition of English and then using it?

12. What are some of your greatest challenges with teaching English to young learners? 
13. What do you think would improve teaching of English to young learners both locally and nationally?

14. What methods would you suggest to improve students; English skills, especially speaking and listening?

15. Do you have any other thoughts or comments? 


\section{Appendix C}

Themes from Coding Teacher Transcripts

\begin{tabular}{|c|c|c|c|}
\hline Codes/Themes & Sub Categories & Public School & Private School \\
\hline \multicolumn{4}{|l|}{ Instructional Methods } \\
\hline & TPR & $\mathrm{L}, \mathrm{M}, \mathrm{C}, \mathrm{P}, \mathrm{K}$ & M,D \\
\hline & Music & $\mathrm{M}, \mathrm{P}, \mathrm{D}$ & M,D \\
\hline & Role play & $\mathrm{L}, \mathrm{K}$ & M,D \\
\hline & Storytelling & $\mathrm{M}, \mathrm{P}, \mathrm{D}$ & M,D \\
\hline & Listen and Repeat & $\mathrm{L}, \mathrm{M}, \mathrm{C}, \mathrm{P}, \mathrm{D}, \mathrm{K}$ & $\mathrm{D}$ \\
\hline & Contextual instruction & $\mathrm{L}, \mathrm{P}, \mathrm{D}$ & $\mathrm{D}$ \\
\hline & Vocabulary & $\mathrm{L}, \mathrm{M}, \mathrm{C}, \mathrm{D}$ & M,D \\
\hline \multicolumn{4}{|l|}{ Other } \\
\hline & Phonics & $\mathrm{L}, \mathrm{D}$ & $\mathrm{M}$ \\
\hline & Scaffolding & $\mathrm{L}$ & $\mathrm{D}$ \\
\hline & Writing & $\mathrm{M}, \mathrm{C}, \mathrm{D}$ & $\mathrm{M}, \mathrm{D}$ \\
\hline & $\begin{array}{l}\text { Questioning- Differentiated } \\
\text { Inst. }\end{array}$ & $\mathrm{L}, \mathrm{P}, \mathrm{D}, \mathrm{K}$ & $\mathrm{M}$ \\
\hline & Cooperative groups & $\mathrm{L}, \mathrm{M}, \mathrm{C}, \mathrm{P}, \mathrm{D}, \mathrm{K}$ & \\
\hline & Daily English & $\mathrm{L}, \mathrm{M}, \mathrm{C}, \mathrm{D}$ & \\
\hline & Memorize & $\mathrm{C}, \mathrm{D}$ & $\mathrm{M}, \mathrm{D}$ \\
\hline & Reading Comprehension & $\mathrm{P}$ & M,D \\
\hline & Culture & $\mathrm{P}$ & $\mathrm{M}, \mathrm{D}$ \\
\hline & Classroom English & $\mathrm{P}, \mathrm{K}$ & $\mathrm{D}$ \\
\hline & Realia & $\mathrm{L}, \mathrm{D}, \mathrm{P}$ & $\mathrm{D}$ \\
\hline
\end{tabular}




\begin{tabular}{|c|c|c|c|}
\hline Challenges & & & \\
\hline & Extra responsibility & L,M,C,D,K & \\
\hline & Range of language ability & L,D & \\
\hline & Time & $\mathrm{M}, \mathrm{C}, \mathrm{D}, \mathrm{K}$ & $\mathrm{M}, \mathrm{D}$ \\
\hline & Training & $\mathrm{C}, \mathrm{D}, \mathrm{K}$ & \\
\hline & Teacher's level of proficiency & $\mathrm{D}$ & \\
\hline & Getting students to speak & L,C,P,D & M,D \\
\hline & Opportunities to speak & $\mathrm{L}, \mathrm{M}, \mathrm{C}, \mathrm{P}$ & $\mathrm{M}$ \\
\hline & Motivation & C,D & $\mathrm{M}$ \\
\hline & Explaining concepts in English & K & $\mathrm{M}, \mathrm{D}$ \\
\hline & $\begin{array}{l}\text { Students' background } \\
\text { knowledge }\end{array}$ & & $\mathrm{D}$ \\
\hline & Asking/using directions & $\mathrm{D}$ & $\mathrm{D}$ \\
\hline & Different language structures & & $\mathrm{D}$ \\
\hline \multirow[t]{7}{*}{\begin{tabular}{|l|} 
Recommendations to \\
increase listening and \\
speaking more English
\end{tabular}} & & & \\
\hline & $\begin{array}{l}\text { More opportunities to listen and } \\
\text { speak }\end{array}$ & L.M,C,P,D,K & M,D \\
\hline & $\begin{array}{l}\text { Radio, TV, movies, } \\
\text { newspapers, computer }\end{array}$ & L,M,P,D & $\mathrm{M}, \mathrm{D}$ \\
\hline & More contact $w /$ foreigners & $\mathrm{M}, \mathrm{C}, \mathrm{P}, \mathrm{D}$ & M,D \\
\hline & More class time & $\mathrm{M}, \mathrm{D}, \mathrm{K}$ & M,D \\
\hline & $\begin{array}{l}\text { English environment English } \\
\text { Village }\end{array}$ & $\mathrm{L}, \mathrm{M}, \mathrm{C}, \mathrm{P}, \mathrm{D}, \mathrm{K}$ & $\mathrm{M}, \mathrm{D}$ \\
\hline & $\begin{array}{l}\text { College students/churches to } \\
\text { provide English }\end{array}$ & $\mathrm{M}$ & \\
\hline
\end{tabular}




\begin{tabular}{|l|l|l|c|}
\hline & instruction/activities & & \\
\hline & Oral exam & C,P & M,D \\
\hline & More training & P,D,K & M,D \\
\hline & Culture & C,P & \\
\hline & Tech equipment & D,K & \\
\hline & Long term teachers & D,K & M,D \\
\hline & $\begin{array}{l}\text { Memorize usable/predictable } \\
\text { phrases }\end{array}$ & K & \\
\hline & National - English immersion & L,M,K & M \\
\hline & Homogeneous grouping & & M \\
\hline & Parental assistance & & D \\
\hline & National curriculum & & D \\
\hline & Class level competition & & \\
\hline & Use of BEP & & \\
\hline
\end{tabular}




\section{Appendix D}

Sample pages used in one private English center - (publisher unknown).

\section{Lesson Five}

\section{skills-Time:}

\section{Reading}

1 Look at the text. Where do the two events happen?

2 Listen and read. (20) 122

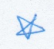

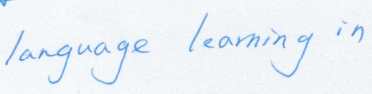

\section{Child Heroes}

\section{Boy helps two friends}

A very strong earthquake hit China on May 12th 2008. Lin Hao, a ten-year-old pupil, was very brave when his school collapsed in the earthquake. After climbing out of his school, he helped out two of his friends. Lin's arm hurt a lot, but he still

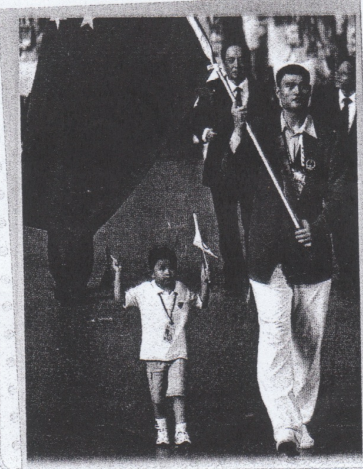
carried his friends. Becouse Lin was a hero of the earthquake, he carried the Chinese flag at the opening of the Olympic Gomes in August, 2008.

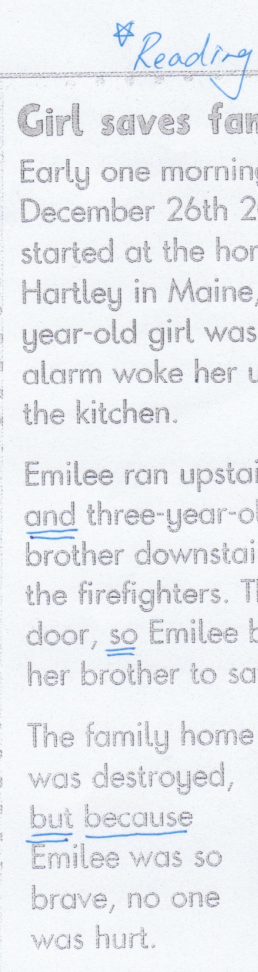
context

\section{Girl saves tamily} Early one morning, on December 26 th 2009 , a fire started at the home of Emilee

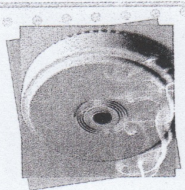
Hartley in Maine, U.S.A. The fourteenyear-old girl was asleep, but the smoke alarm woke her up and she saw smoke in the kitchen.

Emilee ran upstairs to wake up her parents and three-year-old brother. She carried her brother downstoirs while her parents called the firefighters. They couldn't get out of the door, so Emilee broke a window to carry her brother to safely.

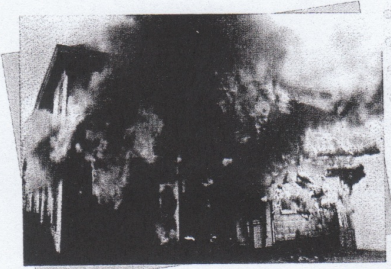

3 Underline these words in the text. Guess their meanings and then check them in the Dictionary.

\section{hero earthquake collapse carry smoke asleep}

4 Read again. Circle the wrong word and write the correct word.

1 In May 2008, there was a strong tsunami. earthquake

2 Lin Hao carried three of his friends.

3 Lin carried the American flag at the Olympic Games.

4 Emilee saw smoke in the living room.

5 Emilee carried her sister out of the house.

100 Unit 13 Words in context: child heroes Reading: two factual accounts 


\section{Lesson Six}

\section{slatls Ittimal}

\section{Writing}

1 Write the lines in the correct order.

Draw a stamp in the correct place.

07842

Martha Lewis

MarthaLewis

Boston

472

Lincoln Street

2 Read the letter and write.

plane pool vacation hospital
beach head hotel

Hi Susie,

17 cook Street

chicago

$5 / 834$

Thanks for

August 3/st

val you have a good summer?

we went by 2

excited. I loved it! we stayed in a

It was really hot and we swam in the

every day. I liked the ocean the most because and the ocean

I tried surfing but it was difficult.

It was a great 5 brother pete fell by the pool and hurt his ${ }^{6}$ one problem. My little go to the ?

$O K$ and he started swimming again.

Did you go on vacation? Where did you go?

Please write soon and tell me all your news!

from,

Alisa 


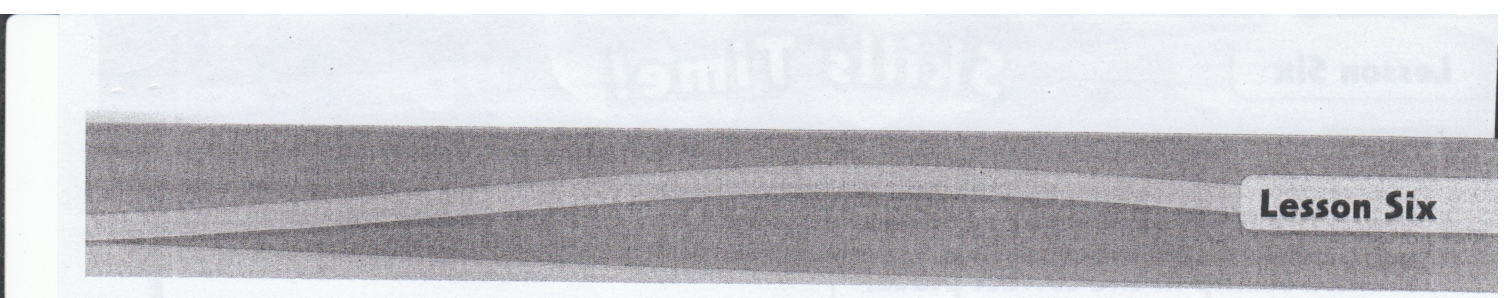

\section{Write an alternative sentence.}

I hope you are well. Dear Atisa, Best wishes, Susie. Tell me your news.

1 Hi Alisa. Dear Alisa,

2 How are you?

3 Write soon.

4 From, Susie.

\section{My writing}

4 Write a reply to Alisa about your vacation or trip.

Write your address

Write the date.

Write a greeting.

Answer Alisa's

questions.

Write about your vacation or trip.

Where did you go?

When did you go?

How did you travel there?

What did you do / eat?

How was the weather?

Write about something that happened.

Write an end to the letter.

Write your name.

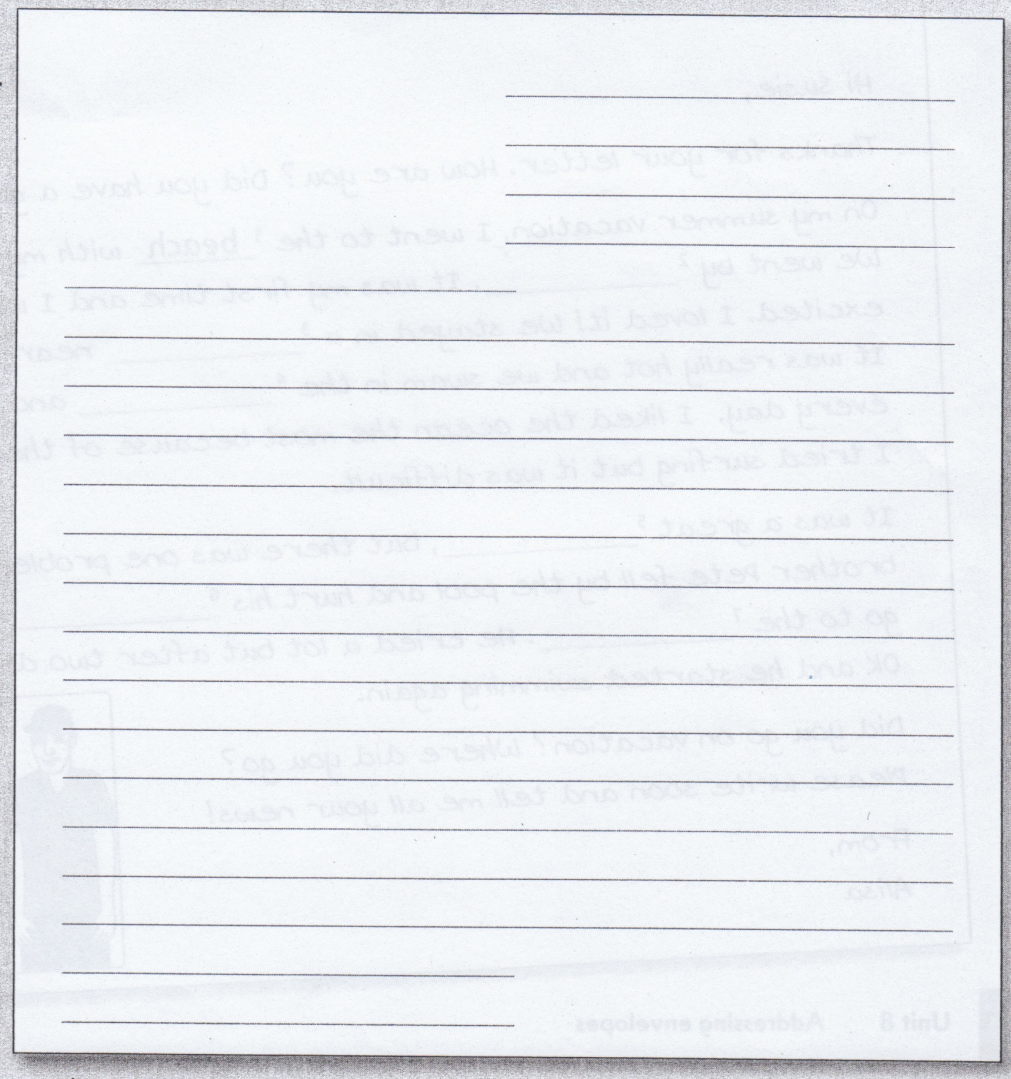




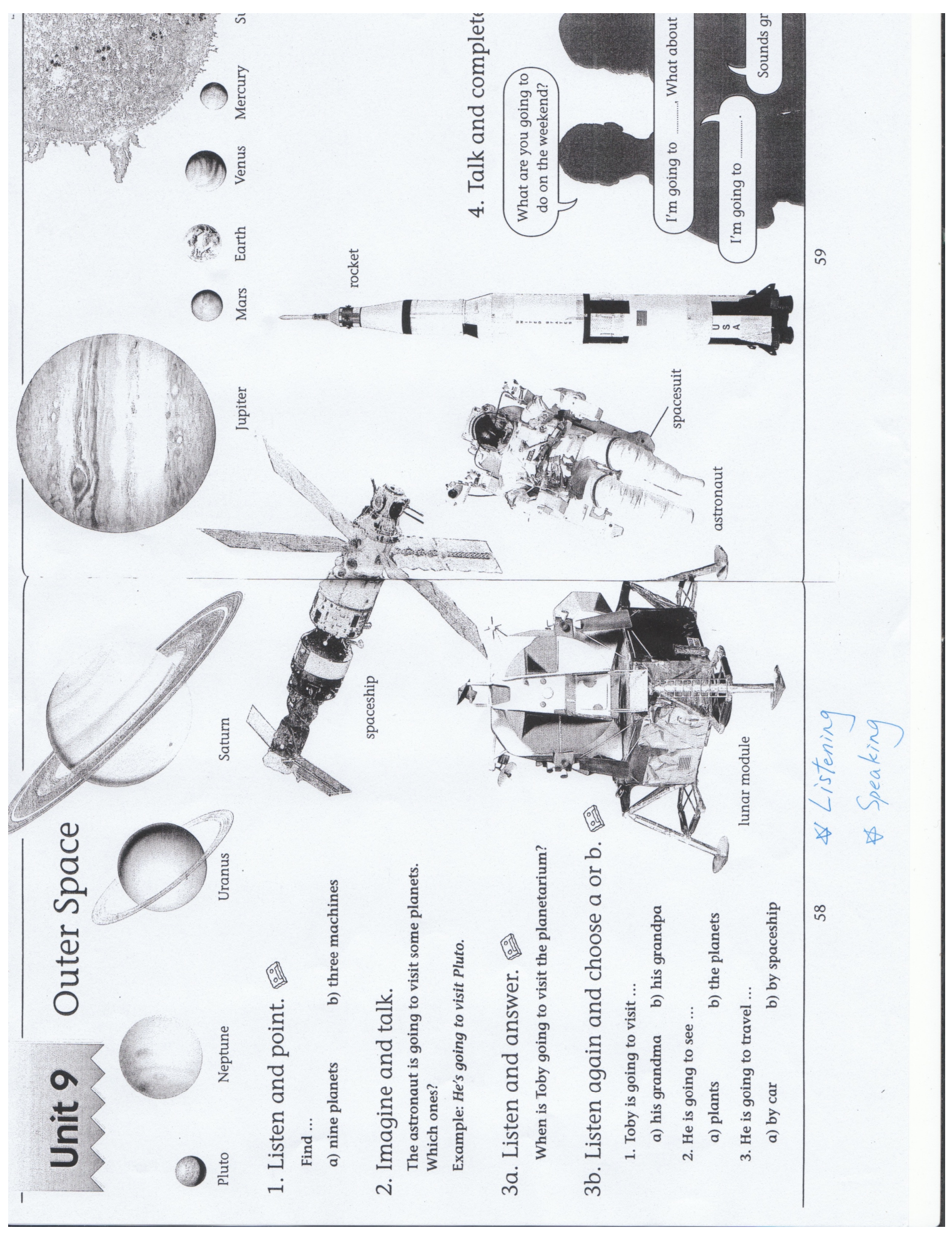


10

(4) Read, look and write.
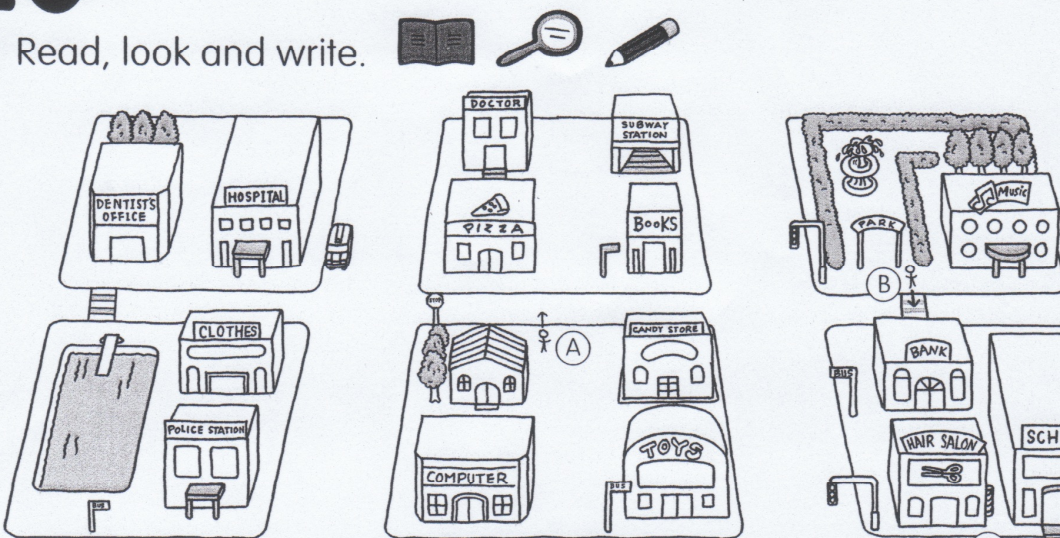

$(B)$
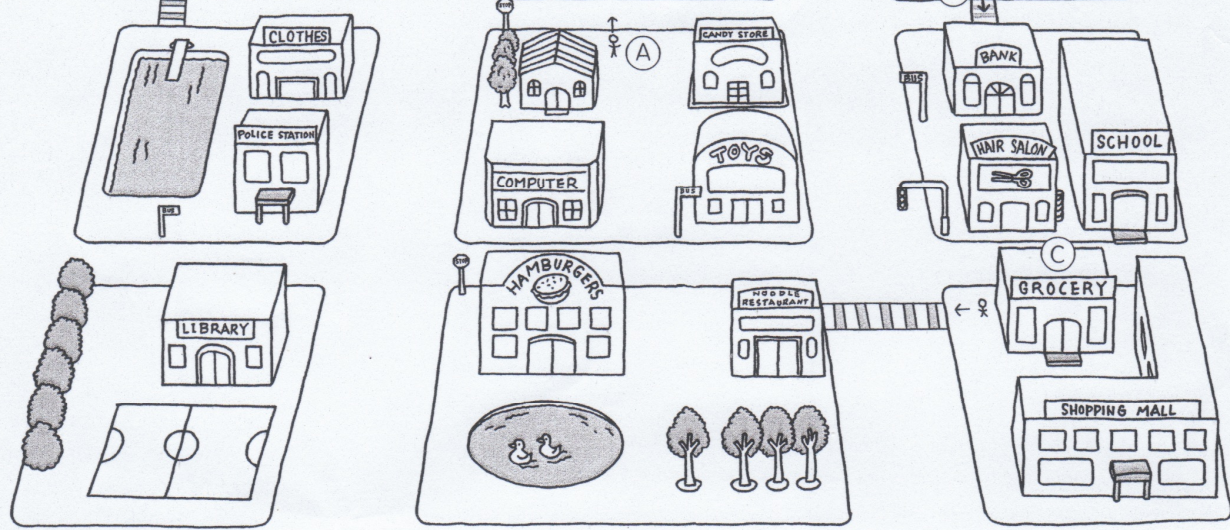

(A) Excuse me. I'm near the candy store. I have a toothache. Where's the dentist's office?

\section{Tum left. Go stroight to the swimming_pool} Cross the street. II's next to the hospital

(B) Pardon me. I'm at the park. Where's the swimming pool? Cross the street

(C) Excuse me. I'm at the grocery store. Where's the subway station? 